2009

\title{
Student Perceptions of Interactive Whiteboards in a Third Grade Classroom
}

Deanna J. Genesi

Cedarville University

Follow this and additional works at: http://digitalcommons.cedarville.edu/education_theses

Part of the Elementary Education and Teaching Commons

\section{Recommended Citation}

Genesi, Deanna J., "Student Perceptions of Interactive Whiteboards in a Third Grade Classroom" (2009). Master of Education Research Theses. 19.

http://digitalcommons.cedarville.edu/education_theses/19 
STUDENT PERCEPTIONS OF INTERACTIVE WHITEBOARDS

IN A THIRD GRADE CLASSROOM

A thesis submitted in partial fulfillment of the requirements for the degree of Masters of Education

By

DEANNA JOY GENESI

B.A. Education, Cedarville University, 2003

2009

Cedarville University 


\section{CEDARVILLE UNIVERSITY}

SCHOOL OF GRADUATE STUDIES

March 1, 2009

I HEREBY RECOMMEND THAT THE PROJECT PREPARED UNDER MY SUPERVISION BY Deanna Joy Genesi ENTITLED Student Perceptions of Interactive Whiteboards in a Third Grade Classroom BE ACCEPTED IN PARTIAL FULFILLMENT OF THE REQUIREMENTS FOR THE DEGREE OF Master of Education.
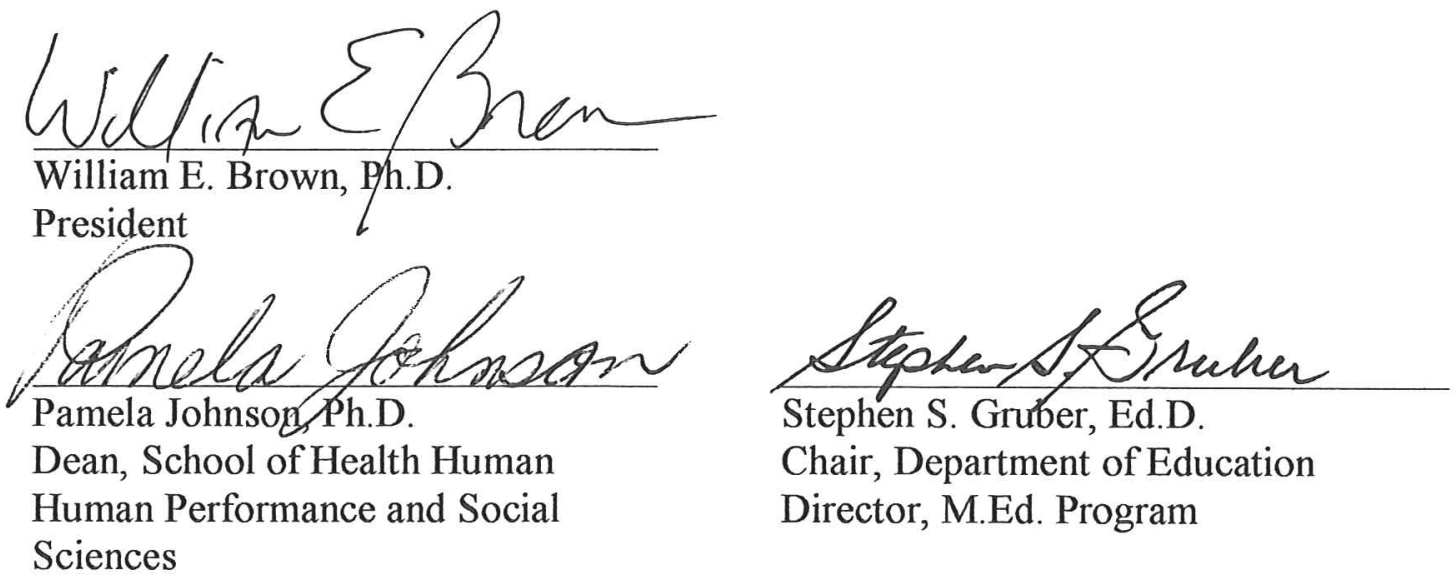


\begin{abstract}
Genesi, Deanna J. M.Ed., Education Department, Cedarville University, 2009. Student Perceptions of Interactive Whiteboards in a Third Grade Classroom.
\end{abstract}

This qualitative project presents students' perceptions of interactive whiteboard (IWB) usage in a third grade elementary classroom. The use of the IWB was alternated with the overhead/chalkboard on an $\mathrm{ABAB}$ design. The study was based on semistructured interviews of 19 rural, elementary school students. The interview questions focused on the following constructs: benefits, limitations, and suggestions for improvement. The results established that students found the IWB to be interesting, fun, and engaging because it involved multi-media aspects and improved visuals. The study also noted the students' perceived limitations of the IWB and areas for improvement. The results of this study can be used to inform other educators on possible uses for the IWB in the primary classroom setting. 


\section{TABLE OF CONTENTS}

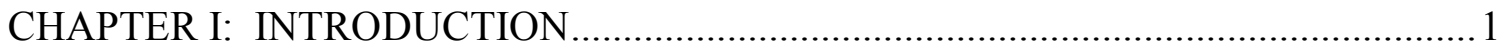

Definition of Terms .............................................................................. 6

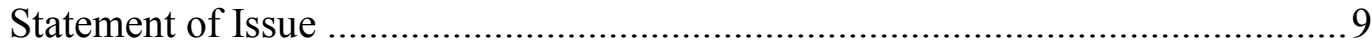

Scope and Study and Delimitations....................................................... 11

Significance of the Study ...................................................................... 12

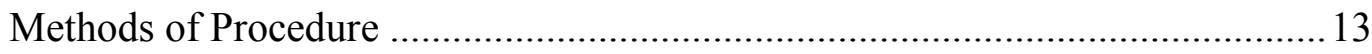

CHAPTER II: PLENARY LITERATURE REVIEW .............................................. 17

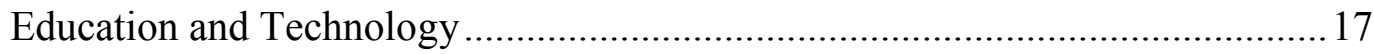

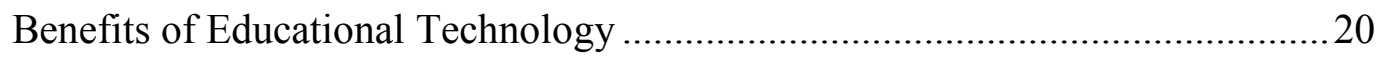

Limitations and Disadvantages of Technology .............................................2 21

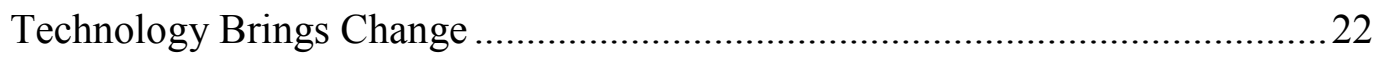

Overview of Information Communication Technologies (ICT) in Education .....25

Implementing ICT in Today's Classrooms - The Benefits...............................28

Implementing ICT in Today's Classrooms - The Barriers ...............................29

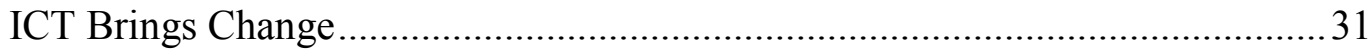

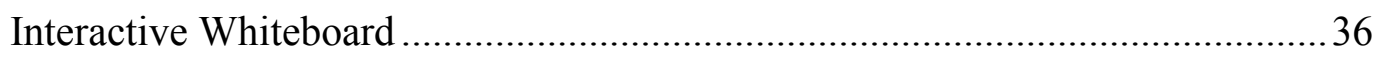

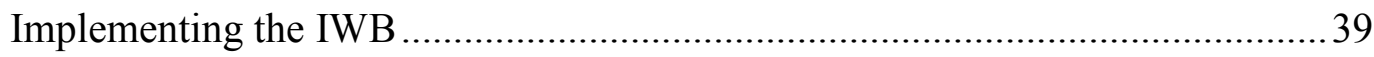

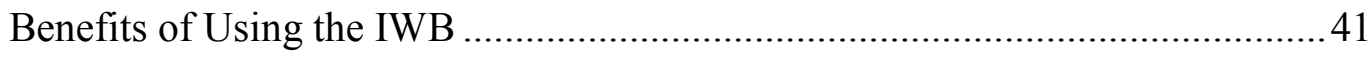

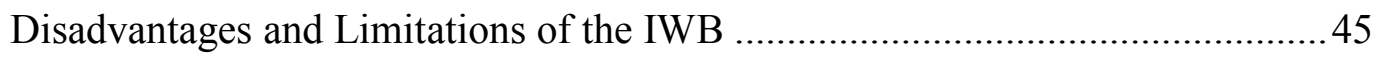

Teachers' and Students' Perceptions ......................................................... 46

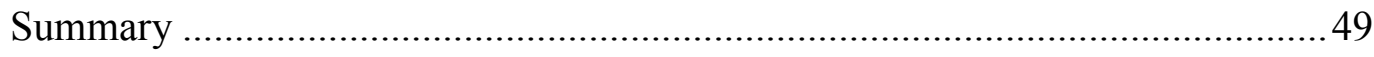


CHAPTER III: METHODOLOGY .................................................................... 51

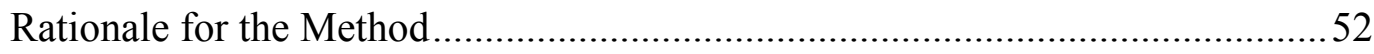

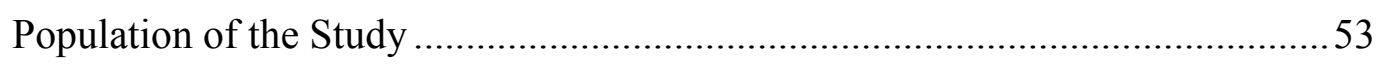

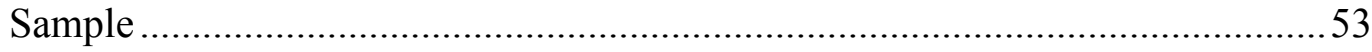

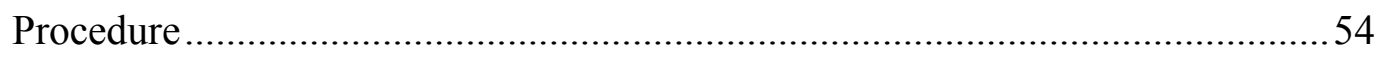

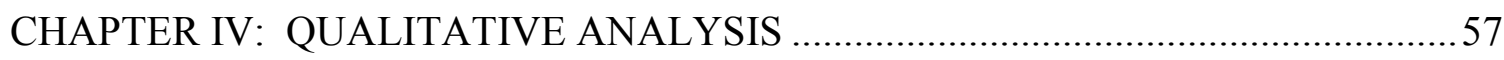

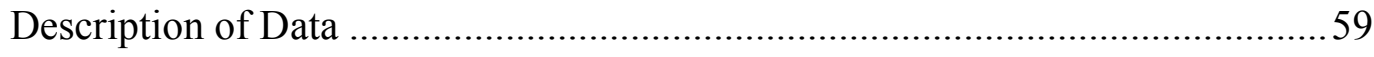

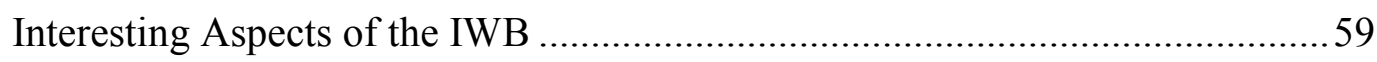

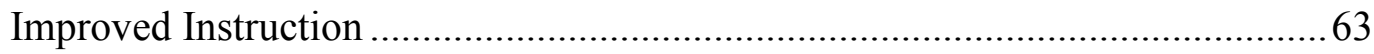

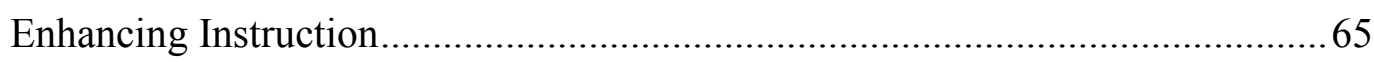

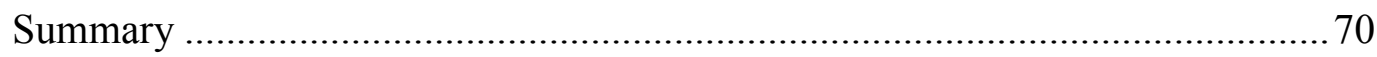

CHAPTER V: DISCUSSION AND IMPLICATIONS ......................................... 71

Interpretation of the Results ................................................................. 71

Potential Applications of the Findings …................................................ 75

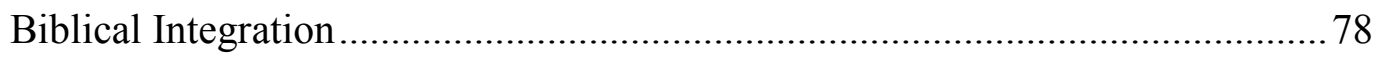

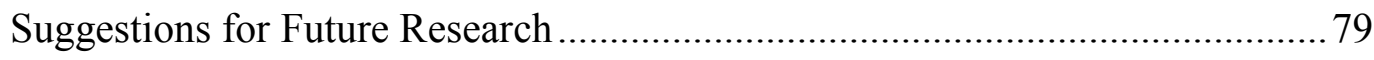

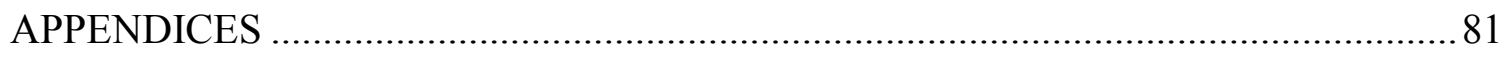

APPENDIX A: Interview Questions .................................................... 81

APPENDIX B: Parental Consent Form...................................................... 84

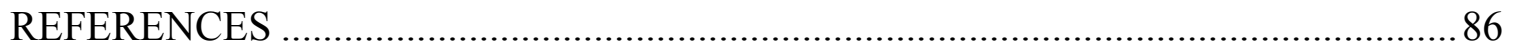




\section{ACKNOWLEDGEMENTS}

First and foremost, I want to thank my Lord and Savior Jesus Christ who has been with me every step of this journey. I could not have completed this project without the constant encouragement I received from His word and the gentle guidance I experienced from His loving hand. This project is proof that "with God, nothing will be impossible."

I would like to thank my family and friends for their prayers and support throughout my entire education at Cedarville University.

I want to give a special thanks to Dr. Stephen Gruber for his encouragement and guidance as I sought to complete my Master's degree at Cedarville University.

I also want to thank Christina (Schut) Sykes for paving the way and setting a wonderful example for me to follow as I replicated aspects of her action research study in my primary classroom setting.

Finally, I want to thank my precious third grade students from Glendale Elementary School. Thank you for your patience with me, and thank you for your eagerness to help me by journaling and participating in individual interviews. I couldn't have done it without you! 


\section{CHAPTER I: INTRODUCTION}

Today's classroom has undergone many changes even over the past several years. While the chalkboard is still used frequently in many classrooms, other methods of teaching instruction, specifically other forms of technology, are being utilized more and

more. According to Villano (2006) and Venezky (2004), teachers are making more and more use out of technology. This technology may include computers, interactive whiteboards, handheld tablets, digital projectors, video-editing systems, software programs, teaching machines, computer assisted instruction (CAI), intelligent tutoring systems, and of course, the World Wide Web. Unfortunately, the vast use of technology does not guarantee success for those who are trained by it (Furr, Ragsdale, \& Horton, 2005). The key to unlocking the power of technology lies in the hands of the teacher who both uses and applies it effectively in the classroom (Fletcher, 2006).

A particular aspect of modern technology today is information and communication technology (ICT). ICT is a tool for instruction that can serve many different purposes. Because of its versatility, ICT cannot be easily classified in its nature or its function. However, ICT can be compared with other more traditional educational resources like books, posters, worksheets, and even video and audio recordings. The implementation of ICT is not meant to replace these common teaching resources because in some cases the traditional way may be the best way (Kennewell, Tanner, Jones, \& Beauchamp, 2008), but the benefits of implementing ICT to enhance teaching and learning cannot be overlooked. 
The value of ICT in the regular education classroom setting has been considered by many different researchers over the past several years. For instance, Venezky (2004) researched the effectiveness of ICT as well as the consequences of ICT use in the classroom. Beauchamp and Parkinson's (2008) studies focused on students' attitudes towards science as they moved from an ICT-rich primary school in Wales in the United Kingdom to a secondary school in the same area with less ICT resources. Their study showed that the use of ICT could prove to be a hindrance if it kept the students from actually investigating and doing hands-on experiments. According to Venezky (2004) a balance must be reached between traditional and technical methods of teaching.

Teachers' views of ICT use in the classroom often vary depending on how familiar they are with ICT. According to Williams, Coles, Wilson, Richardson and Tuson (2000), teachers are more inclined to use ICT resources if they perceive the benefits that it can bring to their instruction as well as to their students' learning. Albirini's research (2006) found that teachers generally have positive attitudes towards ICT in education. In fact, many of the teachers that Albirini interviewed stated that they felt computers contributed to their standard of living and thereby helped them to earn the respect of others. Consequently, they would most likely have a positive view of ICT integration in the classroom. Albirini also found that teachers perceived computers as a practical educational tool that carries with it the potential to bring about improvements in the education of their students.

Generally speaking, students also tend to favor the use of ICT in the classroom. According to Hall and Higgins (2005), students favored ICT because it provided versatility and access to multi-media. Furthermore, students found ICT to be engaging 
and fun, and they appreciated the visual presentations that ICT afforded. Tanner and Jones (2007) found that students valued the bright colorful displays of ICT as well as the opportunity to use new technologies rather than the older, more familiar tools. While students' views about the value of ICT in education often focused on the superficial features of the various forms of technology, students claimed to be more motivated when working with new forms of technology. Students also shared that they liked the immediate feedback they received when working with ICT resources.

While there are many benefits to ICT integration, there are also disadvantages and limitations to its usage in the classroom setting. According to Ragsdale and Durell (as cited in Furr et al., 2005), the use of computers and other ICTs required teachers to monitor and redirect students who saw school computer usage simply as a "time-filler" and not actual learning time. As students worked independently or in small groups at different computers, teachers were not always able to supervise the students as they worked. Computer usage also increased the teacher's workload without giving any promise that the students' work would exhibit the same high quality.

According to Cuban's research (as cited in Furr et al., 2005), even though teachers were excited about ICT integration in their classrooms, they often experienced anxiety and concern due to their lack of knowledge in regards to the new technology that they were being asked to implement into their classrooms. Some of their common concerns included the ease of use; the versatility of the ICT in relationship to the curriculum; the ability to find technical support when needed; and the effects on teacher control, teacherstudent relationships, and student learning. 
Over the years, ICT forms have expanded and grown. One emerging aspect of ICT is the interactive whiteboard (IWB). The British Educational Communications and Technology Agency (BECTA) (as cited in Hall \& Higgins, 2005) provides a clear outline of what an IWB is:

An interactive whiteboard is a large, touch sensitive board which is connected to a digital projector and a computer. The projector displays the image from the computer screen on the board. The computer can then be controlled by touching the board, either directly or with a special pen.

The IWB can be used effectively in many different capacities. Teachers and students alike can write, erase, and perform mouse functions with a pen, a finger, or any other maneuverable, firm surface. Anyone using the IWB can write in digital ink over applications or Web sites. In some school districts, teachers have the available technology to create and prepare lessons at home so their students can also review the same lessons from their homes (Starkman, 2006). Some other particular uses of the IWB include showing video clips, manipulating objects or text, demonstrating a skill or a new piece of software, and creating digital flipcharts. The ultimate purpose of the IWB, however, is to access and use digital resources to benefit the entire classroom (Hall \& Higgins, 2005).

Since IWBs are a relatively new form of ICT, research is slowly emerging about the effectiveness of its usage in the education classroom. Hall and Higgins (2005) published a study of students' perceptions of IWBs in several British primary classrooms. Their study showed that the IWB was perceived positively by both teachers and students. Students, especially, appreciated the versatility of the interactive whiteboard. In other 
words, the IWB could tap into a wealth of other ICT resources (i.e. the Internet, software, video clips, and games) as simply one single piece of technology. The students also enjoyed the multi-media capabilities (sound, color, movement, etc.) because they engaged the students and held their attention during the duration of the lesson. Proper use of the IWB in the primary classroom proved to make the learning process more enjoyable and fun for the students involved.

In another study conducted by Beauchamp and Parkinson (2008), the researchers studied a group of students who attended ICT-rich primary schools and then transferred to secondary schools with less ICT resources. The purpose of their study was to determine whether or not an ICT-rich environment matters to students. As the researchers interviewed the students, they discovered that the students liked the IWB because it was more visible, it allowed for more opportunities to participate in the lessons, and it also gave the students the ability to search for information. As the same students moved on to secondary school with limited access to ICT resources, the students expressed frustration that they were unable to use the resources as they had done in their earlier years. Yet, despite their frustration, the lack of ICT resources did not affect their positive attitude toward the subject material that they were being taught. Beauchamp and Parkinson also found that while the students in their study seemed to enjoy the availability of the IWB, the primary teachers had moved away from doing "real" investigations in science class in favor of actually "presenting" findings. Furthermore, the students grew up regarding science as simply a series of facts to be uncovered rather than being challenged to participate in actual investigations. Their study seems to support the fact that while technology can enhance learning, the ultimate benefits are only 
experienced when technology is properly used. Sutherland et al. (2004) echo the same thoughts. ICT alone does not bring new pedagogies with it that somehow transform teaching and learning. Teachers must learn how to use ICT effectively in daily learning activities in order for the technology to make a difference in the lives of students.

\section{Definition of Terms}

Animation - Animation is the creation of an illusion by rapidly going through a sequence of images (more than 20 times per second) so that an observer perceives it as a smooth motion (Pountain, 2001).

Block-Reveal Technique - The 'block-reveal' technique is a method commonly used in IWB presentations to control the pace of movement through the concepts that are being taught. A block that resembles a screen or blind is placed over the text on the IWB to cover the material underneath. The teacher "pulls down the screen" as he/she is ready to reveal more information (Gillen, Littleton, Twiner, Staarman, \& Mercer, 2008).

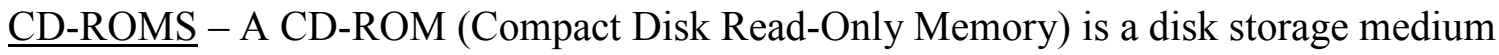
which has a large capacity to store and distribute software. CD-ROMs cannot be written by a computer but can only be pressed by an original master copy (Pountain, 2001).

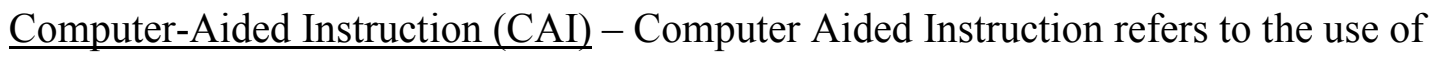
computers to enhance teaching and training courses (Pountain, 2001).

Distance Learning - Distance learning is the process by which students can interact with their teacher(s) and other students over long distances via the Internet (Kirkwood \& Price, 2005).

DVD - A DVD (Digital Versatile Disk) is a read-only disk storage medium similar to a CD-ROM but with a larger data capacity (Pountain, 2001). 
Educational Technology - Educational Technology is a term used to refer the implementation and integration of technology in today's schools. The goal of educational technology is to improve student achievement and ensure that the technology benefits students, teachers, parents, school administrators, and communities nationwide (CEO Forum, 2001).

E-teaching - The term "e-teaching" refers to the new pedagogy that is evolving with the promotion of the IWB in classrooms. "E-teaching" involves the use of ICT to enhance the art of teaching (Kent, 2006).

Hardware - Hardware refers to any physical equipment rather than abstract software that may actually control the machines (Pountain, 2001).

High sensory modality - High-sensory modality refers to the ability to alert the senses in a variety of ways. The IWB has the ability to create high-sensory modality as teachers use special pens to highlight important information so that there is a visible contrast that captures the interests and attention of the students (Gillen et al., 2008). Information and Communication Technology (ICT) - ICT is any type of product that will store, retrieve, manipulate, transmit or receive information electronically in a digital form. This may include word processors, spreadsheets, PowerPoint, digital television and personal computers (Introduction - What is ICT, 2006).

Interactive - In reference to the IWB, the term interactive describes both the technical interactivity with the IWB as an interface between the user and the computer and the pedagogical interactivity as a teaching strategy as the teacher interacts with his/her students (Smith, Higgins, Wall, \& Miller, 2005). 
Interactive whiteboard - An interactive whiteboard is a piece of technology that supports classroom activities in a particular way. The following terms are often used interchangeably with the interactive whiteboard (IWB): "electronic whiteboard," "digital whiteboard," and "smart whiteboard." The IWB consists of a whiteboard, a computer, and a projector that is linked to the computer. Images can be projected onto the screen and students and teachers can add to the images by using whiteboard pen, or in some cases, by simply touching the screen (Clyde, 2004; Hall \& Higgins, 2005).

Internet - The Internet is a network of computer networks that spans the entire world, connecting to other networks. The Internet makes it possible to send email to and from anywhere in the world (Pountain, 2001).

Laptop - A laptop is the largest of the portable computers available today. Laptops may be balanced on the knees but they are too large to hold in one's hands (Pountain, 2001). Liquid Crystal Display (LCD) Projector - The LCD Projector is a type of display that is flat and consumes much less power than the cathode ray tube (Pountain, 2001). This type of projector is often used with the interactive whiteboard.

Multi-Media - Multi-media refers to any media that combines sound, still and moving pictures, and computer software in order to display interactive presentations (Pountain, 2001).

PowerPoint - PowerPoint is Microsoft's presentation software (Pountain, 2001). PowerPoint was designed with the intent and purpose of being used for presentations. However, it's pedagogical usefulness is limited if one doesn't think beyond its most basic presentation capabilities in the classroom and explore the many different ways this piece of technology can be utilized as an educational tool (DenBeste, 2003). 
SMART Notebook - This is a feature of the SMART Board that allows the text to be moved around using the drag and drop facility (Armstrong et al., 2005).

SMART Technologies - SMART Technologies is an industry that was founded in 1987 in order to develop collaborative products for classrooms and meeting/conference rooms. SMART Technologies produced the first SMART Board interactive whiteboard in 1991. (SMART Technologies, 2006).

$\underline{\text { Software }}$ - Generally speaking, software is the term given for any program that a computer can execute as well as all the data that the computers operate on (Pountain, 2001).

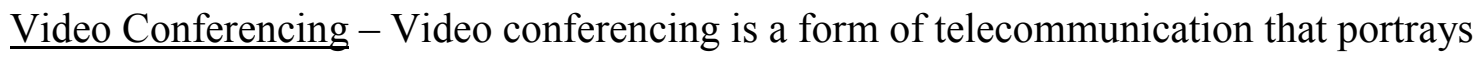
both the image and the voice of the caller (Pountain, 2001).

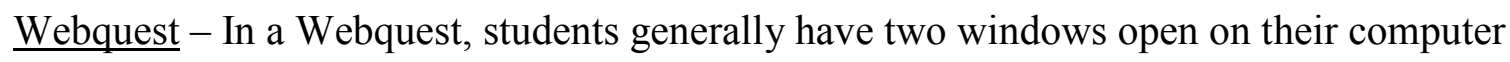
screen. One window is a Word document and the other is the Internet. Students use the Internet to answer the questions on the Word document and fill in the answers as they find them (Lei \& Zhao, 2007).

Word Processing- Word processing is a program that is utilized to create, modify, and print text-based documents. Some common examples of word processors are as follows: MICROSOFT WORD, Lotus Word-Pro, and Corel WORDPERFECT (Pountain, 2001). Statement of Issue

New technology is increasingly available to educators today. Since a great amount of time, money, and effort is invested in technology, it must demonstrate educational value for teachers and students alike in order to justify these added expenditures. Many studies have been conducted to research the effects of using an 
interactive whiteboard in primary classrooms. However, many of these studies have been conducted in foreign lands (Beauchamp \& Parkinson, 2008; Gillen, Staarman, Littleton, Mercer \& Twiner, 2007; Hall \& Higgins, 2005; Wall, Higgins, \& Smith, 2005). Because IWBs are becoming more and more common in today's primary classrooms, research on students' perceptions of the IWB is needed. Researching a particular grade level is beneficial since experiences may vary across different grade levels.

I chose to focus my research on third grade math class. Over the years there has been a plethora of technology resources available that support different teaching and learning strategies and objectives. With the rise of computers, primary and secondary teachers alike have been able to make use of computer programs as they instruct their students concerning new math concepts. This is largely a result of the positive effects of computer-assisted learning. A variety of computers often used in math classes include desk-top computers, hand-held computers, laptops, and personal digital assistants (PDAs). When properly integrated into the math teaching and learning process, these technologies can greatly enhance students' proficiency in math concepts. Other technologies that are often implemented in mathematics classrooms include the following: calculators, immediate response devices, web-based applications, interactive software programs, and the interactive whiteboard (IWB) (Ozel, Ebrar Yetkiner, \& Capraro, 2008).

The IWB is one of the most recent technologies that math teachers and primary teachers alike are looking to in order to present math concepts in a clearer, more distinct way. According to Schweder, Wissick and Mounce (2008), the IWB helps to make mathematics more visual by enabling teachers to demonstrate mathematical processes 
and illustrate new concepts. The IWB also allows teachers to draw on other resources, such as computer software programs, Internet sites, interactive games and manipulatives, and additional web resources. A new method of teaching, "e-teaching," has been coined to describe the new teaching style that has evolved as a result of the use of the IWBs. "Eteaching" involves the use of ICT to enhance the art of teaching students and provides a wealth of possibilities for the teacher who is willing to put forth extra effort to develop new and exciting lessons for his students. Particularly in the area of mathematics, the IWB allows teachers to present new knowledge as problematic, leaving it open to numerous interpretations. In other words, teachers can lead discussions that probe students' understanding of mathematics concepts without being limited by their students' arithmetic abilities (Kent, 2006). The IWB has the potential to enhance the teaching of mathematics. In order to assess this possibility, student perceptions of the benefits and limitations of the IWB in a third grade math classroom were researched.

\section{Scope of the Study and Delimitations}

In this study, I collected data on students' perceptions of the benefits and limitations of the IWB's use in a third grade classroom. I also took into consideration the students' suggestions for how to improve the use of the IWB in the classroom. This study was performed in a rural, public elementary school with an enrollment of approximately 425 students. The student population consisted of approximately $99 \%$ Caucasian students and 54\% economically disadvantaged students (i.e. students eligible for free and reduced-price lunches). The project focused on third grade students in a regular education classroom during math class only. Regarding the IWB, all of the teachers, including myself, were required to attend a basic training session for the IWB in 
the summer of 2007. Several teachers were very familiar with the IWB's use and they were able to assist teachers as needed. Due to the scope of this study, the reported results are reasonably generalizable to other populations of public rural third grade students with demographics similar to that of the study's sample.

This project focused only on my third grader's perceptions of the IWB in math class. Teacher perceptions were not considered as a part of this present study. Furthermore, other subject areas were not included in the study. It is important to note, however, that my students did experience the use of the IWB in other subject areas throughout the course of each day in my classroom, regardless of whether or not the IWB was being implemented for math class that day. Consequently, the use of the IWB in other subjects may have influenced their perceptions of the IWB as it was employed in my classroom. Since the purpose of the study was to describe students' perceptions, I did not track their academic process as a part of the study.

\section{Significance of the Study}

With the rising use of various forms of technology like IWBs in the classroom, it is imperative to investigate the perceived benefits of the IWB by students for several reasons. If the students do not perceive the IWB as valuable, then the technology should be questioned and further investigated. It may be that teachers or administrators need to make some adjustments in their use of the technology to make it more effective in the classroom setting. On the other hand, if the students perceive the IWB positively, recognizing its value as an instructional tool, then its use should be further promoted and encouraged. Extensive research has been conducted in regards to students' perceptions of the IWB in primary classrooms. However, many of these studies (Beauchamp \& 
Parkinson, 2008; Gillen et al., 2007; Gillen et al., 2008; Hall \& Higgins, 2005; Kirkwood \& Price, 2005; Shenton \& Pagett, 2007; Tanner, \& Jones, 2007; Wall et al., 2005) were conducted in countries other than the United States. Therefore, it is necessary to explore American primary students' perceptions of the IWB's benefits and limitations, specifically in a third grade math class.

As with any other new piece of technology, the IWB brings with it limitations as well as benefits. In order to maximize the use of the IWB in the primary classroom, it is necessary to analyze any limitations that the students perceive. Knowing these limitations will prove advantageous to educators as they seek to make improvements where they are needed. Perceived benefits should be weighed against the limitations in order to determine the IWB's effectiveness in the classroom. The results of this action research may provide useful and timely information for other third grade teachers.

In addition to analyzing the students' perceived benefits and limitations of the IWB, suggestions for improvement were also suggested by the students. Technology is not always used effectively and the IWB is no exception. Consequently, student input regarding the use of the IWB will prove to be invaluable as they share trouble spots that can point to areas that need improvement.

\section{Methods of Procedure}

\section{Research questions:}

1. How do third grade students perceive the benefits and limitations of the IWB when compared to traditional instruction?

2. In what areas do third grade students see needs for improvement of the IWB's use in math class? 
This action research focused on my students' perceptions of the IWB as it was used to teach math class. The study was conducted in a qualitative manner. The research was approached inductively as I collected the data first and then formed my hypotheses from the information I had gathered. The data was collected in the form of written journals and student interviews. As I analyzed the data, I sought to evaluate themes regarding the perceived benefits and limitations of the IWB. I also looked for areas where the students communicated the need for improvement. As a field study, this project was conducted in the natural environment of my third grade classroom.

My sample included my third grade classroom which contained all Caucasian students, with the exception of one Egyptian student. My class included a total of 19 students. Journal entries and individual interview data was collected from each child. The actual study lasted for a total of eight weeks and was conducted using an ABAB design. I alternated my use of the IWB for math instruction equally. The following pattern was established:

\section{Miss Genesi's Third Grade Math Class:}

2 weeks IWB/ 2 weeks no IWB/ 2 weeks IWB/ 2 weeks no IWB

My math class convened at the same time each day for a total of 90 minutes. A math meeting exercise occurred each morning from 9:00-9:30 and the actual math lesson occurred each afternoon from 1:15-2:15. The main use of the IWB during the math lessons included PowerPoint presentations, SMART notebook presentations, and the manipulation of objects. When the IWB was not utilized, the following visuals were 
implemented: drawings on the chalkboard, posters, handouts, and the overhead projector. The chalkboard and posters were the main method of presentation for those particular periods of time. The focus of this research project was to determine the students' perceived levels of enrichment and motivation that the IWB created in math class.

During the eight weeks of data collection, the students kept running journals of their math experience with regards to the use of the IWB as well as the absence of the IWB. The students wrote in these journals at least three times per week. Some students went beyond the minimum requirement and wrote in their journals for four or five days. The journals were kept in each student's desk in the classroom. In each journal entry, the students wrote about their experiences that day in math class. Each student was asked to answer four questions which resulted in comments concerning the tools used for instruction, the benefits and limitations of the presentation (i.e. IWB or other visuals), and suggestions for improvement. At the end of each week, I collected the students' journals, read through their comments and then typed them onto a Word document in order to compare the students' comments and look for common themes. All of the journal entries were organized by date which allowed me to compare the students' reactions to either the IWB or traditional teaching for each day. At the end of the eight weeks, I conducted 10-15 minute semi-structured interviews with all of my third grade students. The interviews focused on three main constructs: benefits, limitations, and suggestions for improvement. A second round of interviews was conducted on a select group of students. All of interviews were tape recorded and transcribed for later analysis. As I analyzed the data, I began the process of coding during which I looked for common themes among the three constructs. As I continued to analyze the data, I added 
any emerging codes and removed codes that were not consistently repeated. Finally, I assessed the data for any findings that were repeated throughout the individual interviews. Themes were only included if they were consistently supported throughout the course of the study. 


\section{CHAPTER 2: PLENARY LITERATURE REVIEW}

Technology permeates our nation. Interactive whiteboards (IWBs) are just one specific aspect of technological history. The implementation and utilization of the IWB in many schools across America today has impacted the lives of many students. Some may wonder how technology is used in American classrooms and even question its necessity or effectiveness. A broader look at technology and its impact on education helps place the IWB technology into its proper context.

\section{Education and Technology}

Technology is rapidly changing the way we live and work. The field of education is no exception. In fact, during the late 1990s, new technologies were being invented and designed almost monthly. Technology was abuzz and education was the primary target for those eager researchers who wanted to see if their product could transform education as we know it. Almost a decade later, the novelty of educational technology has somewhat worn off. Many schools are struggling to make ends meet, cutting costs wherever possible. Financial struggles are still a reality today for many school districts. Yet even for those schools with limited financial resources, educational technology is still a prevalent part of education today (Vail, 2003).

Over the years, our nation has felt the pressure from other countries who are continuing to successfully integrate information and communication technologies (ICTs) into the education of their students. In order to prepare our students to thrive in the digital age, the United States has made a commitment to provide students with the skills 
and resources they will need to succeed in life (CEO Forum, 2001). According to the CEO Forum, educators are encouraged to make the best use of available technology in order to benefit our nation's schools, surrounding communities, and most importantly, our students. Today's students need to be taught twenty-first century skills that they will need in order to thrive in the future. Some of these skills include digital literacy, inventive thinking, effective communication, teamwork, and the ability to create highquality projects. In order to do reach this lofty goal, educators need to focus technology on the key building blocks of student achievement. Those building blocks include assessment, alignment, accountability, access, and analysis.

Just as educators should consider the building blocks of student achievement, it is also important that they consider the many facets of education. One vital aspect to reflect on is how students learn. When teachers know how their students learn best, real authentic learning begins to take place and students are prepared and equipped for their future. Driscoll (2002) argued that while technology integration in schools is not easy, it is necessary. She provided four broad principles as a framework for teachers as they think about how to integrate technology into their daily instruction. These four principles were as follows: 1) Learning occurs in context, 2) Learning is active, 3) Learning is social, and 4) Learning is reflective. It is important to remember that technology by itself will not guarantee true learning. However, the proper use of available technologies does have the power to enhance and transform education in today's classroom.

Even with all the positive assumptions about the effective use of technology in the classroom, technology still tends to be viewed almost timidly by many educators today. Educators are often inclined to be traditionalists; therefore, they are not as eager to latch 
on to the newest and latest technological advancement that has just come out on the market (Vail, 2003). Another factor that contributes to educators' hesitancy in regards to technology is that they don't want to embrace a new technology until they see a need for it. With the passing of the No Child Left Behind Act (NCLB) in 2001, however, educators' perspectives were bound to change. In fact, Vail argued that it would be nearly impossible for schools to meet the demands that are placed upon them without implementing technology in the classroom.

As with any issue, there are usually two sides of the coin. The same is true for educational technology. It is important to recognize the differences between the quantity of technology use (how much technology is used and why) and the quality of technology use (how technology is used and why). In past research, the focus has been mainly on the quantity of technology use. However, it is just as valid a question to consider the quality of technology use in schools today. In fact, recent research indicates that even when technology is used at a certain frequency, not all technologies are found to be beneficial, constructive, or helpful (Lei, \& Zhao, 2007). It is important that educators realize that the simple use of educational technologies alone does not guarantee that teaching and learning will somehow be transformed. Teachers must use technology efficiently and bring new pedagogies to their instruction. The combination of new pedagogies with technology use is what leads to improved teaching and increased student learning (Sutherland et al., 2004). Lei and Zhao (2007) emphasized that technology is an artifact, a product, and a tool. It has the capacity to accomplish certain tasks, but that potential is only realized when it is connected with specific problems. In other words, someone must use the technology correctly and efficiently for any benefits to be experienced. Secondly, 
technology use is dependent on the context of the situation and is closely connected with the users. In other words, the same technology can be utilized in several different ways depending upon the purpose of the one who is using the specific technology. Thirdly, technology use is in constant change while technology is in a static stage. Finally, technology use allows original technologies to take on various forms and uses.

Ultimately, technology use is technology-in-context. Levin (as cited in Lei \& Zhao, 2007) suggested that there are four categories in which technology may be used. These categories are as follows: 1) technology as media for inquiry, 2) technology as media for communication, 3) technology as media for construction, 4) and technology as media for expression.

\section{Benefits of Educational Technology}

Generally speaking, educational technology helps to create a rich, studentcentered learning environment with a vast variety of wonderful opportunities for studentcentered learning (DenBeste, 2003). Furr et al. (2005) acknowledged the benefits of educational technology, including but not limited to enlivening the classroom setting, stimulating learning, providing immediate feedback for students, allowing students to work in small groups with their peers (either in the classroom setting or globally), and creating a classroom environment where the teacher's role is that of facilitator rather than lecturer.

Another benefit that educational technology brings is increased parental involvement and teacher professional development. For example, with the aid of technology, parents are able to communicate with teachers and view their child's assignments, attendance, and work online. Furthermore, educators can engage in 
professional development through the use of technology as it is made accessible to them anytime, anywhere (CEO Forum, 2001).

Educational technology increases students' abilities to apply and produce knowledge for the real world. These real-life contexts can be presented with the use of technology, making the classroom come alive. As students are challenged to take ownership and responsibility for their learning, they find themselves becoming more and more engaged in the learning process than ever before. In fact, as students seek to access more information through technology, they are able to deepen their knowledge so that they can meet their own personal needs and interests. Technology presents a challenge to students to go beyond just accepting information because it was presented in a textbook. Students in classrooms where technology is implemented well will apply research skills and seek evidence to support what they are learning. (CEO Forum, 2001).

\section{Limitations and Disadvantages of Technology}

While educational technology has the potential to enhance both teaching and learning, it is clear that these technologies are not always used to their full capacity. The challenge remains to adapt teaching strategies to the new technologies in ways that elicit and increase student learning and understanding (Lawrenz, Gravely, \& Ooms, 2006). Computer technology is simply a tool, just as is a language, or pencil and paper. While it has its many benefits, the educator should anticipate unplanned side effects (both good and bad) of educational technology that often surpass the original intentions (Furr et al., 2005).

Another major downside to using technology in the classroom remains the time issue. Instructing students in the use of technology and creating resources to use with 
instruction takes an enormous amount of time and effort. Furthermore, it is of utmost importance that educators choose the type of technology that best suits their educational goals. Technology used simply for the sake of technology may "look good," but it will most likely be pedagogically useless (DenBeste, 2003).

Educational technology can cause a "knowledge divide," as only some students have access to the educational tools and learning that foster developing the skills needed for the twenty-first century. This presents a challenge to both the state and federal governments to continue to monitor and eliminate inequities in regards to the accessibility to educational technologies (CEO Forum, 2001).

If educational technology is to be used effectively, schools districts must also provide sufficient and continuous professional development for educators so that they are knowledgeable with any technology that they are being encouraged to integrate into their classrooms (CEO Forum, 2001).

\section{Technology Brings Change}

Research on the impact of technology in education is relatively new, yet there is sufficient evidence that educational technology helps to bring about changes in the processes of teaching and learning in classrooms. For example, technology has the potential to transform the learning environment from one that is teacher-centered to one that is student-centered. Other changes brought on by educational technology include a problem and project-centered environment that is collaborative, communicative, and productive. All of these characteristics help to foster a digital learning environment where it is possible to develop the skills needed to live in the twenty-first century (CEO Forum, 2001). 
While technology use is valuable and desirable in today's classrooms, there is a fine balance between spending too much time using technology and spending too little time using educational technologies. Research conducted by Lei and Zhao (2007) indicated that students benefited from spending up to about 3 hours per day using computer technologies, but when they spent too much time (over 3 hours) using computer technologies, the benefits seemed to be cancelled out and unrealized. This research indicated that although the amount of time spent using educational technologies may have a general effect on student achievement, another factor to consider might be how the students spent their time as they used these technologies. Once again, the quality of technology use seemed to be more important than the quantity of technology use.

As educators seek to teach with technology in order to prepare students for the future, it is imperative that new assessments are implemented which reflect the changing pedagogical practices. Educational technology provides a variety of authentic assessments so that students are presented with more challenging and engaging tasks that will measure higher-level thinking skills. New technological assessments provide a more holistic picture of teaching and learning over time (CEO Forum, 2001).

Technology does bring change, and there is a marked difference in the environment of a multimedia classroom (a classroom which integrates cutting-edge instructional technology to enhance students' learning and engage them in the use of multimedia to construct and convey what they have learned) versus a traditional classroom (a classroom equipped only with a chalkboard and pull-down ceiling screen). Does either environment make a more positive impact on the students' perceptions of the learning achievement of students or on their perceptions of the instructional technology? 
A recent study which compared the perceptions of college-aged students who took classes in multimedia classrooms and students who took classes in traditional classrooms claimed that there were no considerable differences. However, the researchers did find that the students who were enrolled in the multimedia classrooms had more positive perceptions of their instructors' teaching methods than those students who took classes in the traditional classroom. Students who were interviewed at the end of the study commented that while technology can help the learning process, ultimately it is the instructor who makes the difference. Other students claimed that it was easier to pay attention and the lessons were more interesting when the instructor used a variety of multimedia teaching tools rather than relying solely on the textbook. Students also shared that using technology made the information seem more real. They felt that the media being used gave them an advantage over other students taking the same class in a traditional setting (Zhang \& Deng, 2004).

While technology does incite change in the classroom environment, Kirkwood and Price (2005) challenged teachers and school administrators to continue to develop a better understanding of technology and the issues that often surround it so that innovations are not driven by technology alone. Technology is an important aspect to consider, but it is just as vital to consider educators' access to pedagogic models and processes as well as the contexts in which the students engage with technology. Technology by itself is unlikely to improve education. However, learning can be enhanced greatly when new innovations take the characteristics of the new technology and the pedagogic design into account along with the context within which the learning is taking place, the students' characteristics and their previous experience, and their 
familiarity with the technology involved. Technology on its own cannot ensure that effective learning outcomes are achieved; rather it is the educational purposes set out by the educators that must lead the way.

Overview of Information Communication Technologies (ICT) in Education

Most educational technologies today fall under the category of Information Communication Technologies (ICTs). ICT covers any product that can store, retrieve, manipulate or transmit information electronically in a digital form. Some examples of ICT include Microsoft Word, Excel, PowerPoint, Adobe Indesign, Photoshop and Illustrator, email, video conferences, digital cameras, CD-ROMs, fax machines, and of course, the World Wide Web (Introduction-What is ICT, 2006; Williams et al., 2000). ICT is a multi-faceted and resourceful tool that is not easily classified in nature or function. However, it can be compared with other educational resources like books, posters, worksheets, and videos which help stimulate, structure, and support learning activities in the classroom. ICT is not meant to replace these more traditional tools of education. In fact, there are some cases where the traditional approach may be more suitable. However, when integrated effectively, ICT can be used in combination with traditional resources in order to provide the best learning environment possible (Kennewell et al., 2008).

As mentioned earlier, ICT is simply a tool for educators to implement and integrate into their daily instruction. As research shows, ICT is not a means in and of itself. ICT does not cause learning to take place. As one teacher shared in an interview, ICT is simply another tool. It is the teacher's responsibility to take the time to learn how to use it effectively (Sutherland et al., 2004). 
ICT integration in classrooms is becoming more and more prevalent in schools today. Every classroom, however, has its own unique culture which ultimately affects how ICT is integrated and implemented into daily instruction. The classroom culture is influenced by a vast variety of people and circumstances. There are national and global influences, not to mention the influences of the school culture and subject culture. Outside cultures that the students bring with them to the classroom must also be considered. As teachers attempt to integrate ICT into their daily instruction, they often adapt their teaching strategies in ways that will fit with the particular culture or cultures in which they find themselves. A good example of this need to adapt ICT to a particular culture is found by comparing how elementary teachers implement ICT in their classrooms versus how secondary teachers implement ICT in their classrooms. For example, in a recent study, Sutherland et al. (2004) found that elementary teachers were more apt to create communities of learning where both students and teachers tapped into a wealth of ICT tools to construct knowledge. The researchers claimed that this may be in part because primary teachers often fail to see themselves as experts in a particular subject domain as secondary teachers often do. Consequently, primary teachers may have an advantage in that they are more prone to favor a co-construction of knowledge approach which is ideal when integrating ICT in the classroom. Williams et al. (2000) also researched ICT usage among both elementary and secondary teachers. Their research showed that both elementary and secondary teachers made use of ICT in the classroom context. However, their study reported that while both elementary and secondary teachers used ICT at a similar frequency in the classroom, secondary teachers 
used ICT more in the areas of professional development, personal use, and administration.

When considering how ICT is used in schools today, it is also important to consider the teachers' personal attitudes and the cultural perceptions of technology that they bring with them to the classroom. Albirini (2006) conducted a study to determine high school EFL teachers' attitudes toward ICT in Syrian education and then investigated the relationship between their attitudes and the factors thought to be influencing them, one of those factors being cultural perceptions. He discovered that most of the teachers felt that computers would contribute to improving their standard of living. These teachers also shared that they felt knowledge of computers would earn them the respect of others and ensure them certain privileges. His findings were not all positive, however. Albirini also found that while his respondents found ICT to be appropriate, they felt that there were other social issues that should be addressed first. The same teachers also commented that computers are propagating too fast and that an alternative computer might better suit their Arabic culture and identity.

Williams et al. (2000), found a significant correlation between levels of ICT use and teachers' attitudes. Their study showed that those teachers who were more inclined to see the benefits of ICT use for themselves and their students tended to use ICT more often. Those teachers who were prone to experience problems and worries tended to use ICT less because the difficulties and mishaps seemed to outweigh the possible benefits. Interestingly, Williams et al. also found that attitudes toward ICT varied among subject teachers. Their study showed that those who taught mathematics or science had a more negative attitude toward ICT, while those teachers who taught business and management 
classes had a more positive attitude towards ICT. ICT use does depend on many factors, as mentioned above. A few other factors that contribute to ICT use in the classroom include the availability of computers at home and/or in the teacher's personal time. Another factor is the availability of portable computers for use in the teacher's own time. In the end, Williams et al. found that teachers are ultimately the most important agents of change in the classroom.

Implementing ICT in Today's Classrooms - The Benefits

There are many benefits of implementing ICT into today's classrooms. It is important to consider both student perceptions and teacher perceptions when analyzing the benefits of ICT.

Students' perceptions of ICT have been a focal point of research in regards to ICT usage in today's classrooms. Kirkwood and Price (2005) saw the significance of understanding students' perceptions of ICT because they claimed that the educational benefits that the students perceived as gains from using ICT were more important than the inherent characteristics of any particular product or medium.

Beauchamp \& Parkinson (2008) conducted a study in a rural part of Wales in the United Kingdom. Their study began in an ICT-rich primary school setting and ended in a secondary school with fewer ICT resources. The study was conducted in order to determine if students' attitudes towards school science changed as they transferred from an ICT-rich environment to one with fewer resources. Their interviews with the primary students gave some valuable insight to student perceptions of ICT in the classroom. Some of the students' perceived benefits of an ICT-rich environment were better visibility and increased student participation. 
Teachers' perceptions of ICT use have also been researched in many different studies. Williams et al. (2000) found that half of primary teachers and $69 \%$ of secondary teachers reported that ICT has had an impact on their teaching, although there were some variations on the secondary level between different subjects. In regards to the impact of ICT on students' learning, the majority of teachers $(62 \%$ of both primary and secondary teachers) thought that ICT had a positive learning effect. Albirini (2006) found that teachers had positive attitudes towards ICT and perceived it as an asset to education. They viewed ICT as a viable educational tool that has the potential to bring about improvements not only to their own classrooms but to their whole school community. Albirini also found that teachers' perceptions of the compatibility of ICT with their current teaching practices were not as positive. Many teachers in his study were unsure about whether or not computers fit well with their curricular goals. Teachers also felt that their class time was too limited for computer use.

Implementing ICT in Today's Classrooms - The Barriers

Implementing ICT into classroom instruction is not without its barriers and limitations. According to Williams et al. (2000), the main reason given by primary teachers for not using ICT was the lack of availability of ICT resources. Access to technology tended to override all other factors in determining the amount of ICT implementation.

There are, however, other factors that inhibit ICT use in the classroom. For example, Albirini (2006) noted that many teachers felt inadequate when asked about their computer competence. Because many teachers lack confidence in regards to using computers and other forms of ICT, it naturally follows that there would be some 
hesitancy on behalf of teachers who are required to implement ICT into their daily instruction. Other similar barriers given by primary educators are a lack of familiarity with ICT resources and a lack of skills in order to implement them effectively (Williams et al., 2000). Consequently, this lack of confidence deems that education administrators make the extra effort to provide training sessions and professional development in regards to ICT use before these teachers are expected to use the technologies in their classrooms. These training sessions, however, add an extra financial burden to many school districts.

Another barrier to ICT implementation perceived by the teachers was the mismatch between ICT and the current curriculum and the class time frame. Simply having access to computers was not enough to achieve educational change. Teachers would benefit from additional planning time so that they could experiment with new ICT technologies (Albirini, 2006).

It would seem that cost or lack of technical support would be strong inhibiting factors to ICT use in the classroom. In many situations, that may be the case. For example, Venezky (2004) reported that one of the three main barriers to ICT adoption in schools was infrastructure limitations, which especially included technical support. Some of the other infrastructure limitations were the placements of the computers as well as the policies that govern student and teacher access to those computers. Yet, Williams et al. (2000) found that these factors were minor compared to the lack of availability and lack of access to technological resources. 


\section{ICT Brings Change}

As previously mentioned, there are benefits and barriers to implementing ICT in the classroom. In order to implement ICT effectively, change is inescapable. According to Wheeler (2001), new technologies have provoked an entirely new and positive dimension to the art of teaching and learning. These changes, in turn, require a great investment by educators in the areas of time, effort, and overall commitment.

Successful implementation of ICT requires a balance between both the school's infrastructure and the competencies of its teachers. During the initial stages of ICT implementation, it is of utmost importance to have a reliable and user-friendly infrastructure to work with. However, as teachers become more technically competent, the shift towards more training opportunities in regards to ICT implementation and pedagogical abilities is necessary. The research shows that the most beneficial staff development programs were the ones that taught both ICT skills and related pedagogical skills (Venezky, 2004). A study conducted by Williams et al. (2000) asked teachers to share ideas for how to make future ICT training more effective and beneficial.

According to these teachers, future training sessions should be flexible, allowing teachers to choose trainings that best fit their needs. These sessions should also be designed to increase familiarity with a wide range of ICT resources, and they should be focused on the types of ICT resources that are currently available in their school.

While there is definitely a need for training in regards to ICT development among teachers, Venezky (2004) argued that equal emphasis needed to be placed on administrative training for knowledge management, teamwork, and communication relations among teachers and administrators. Beyond these changes, it is also vitally 
important to learn how to create an environment where students feel safe to try new things and make mistakes. In order to successfully implement ICT in the classroom, teachers and administrators must remember that whether we embark on a new journey to include ICT resources, or whether we circle back to more traditional methods of teaching, the end result of the efforts made will ultimately be not from the power of ICT, but the power of the creative and imaginative mind that is willing to think "outside the box" to create the best learning environment possible for the students (Venezky, 2004).

Ultimately, ICT causes fear for some educators because technical education can seem to be overwhelming, compared to the more traditional forms of education. While ICT implementation does bring change to the classroom, Venezky (2004) suggested that a balance is needed between activity-laden projects and virtual experiences versus more traditional forms of learning, such as lectures, practice sessions and classroom discussions.

ICT implementation also brings changes for the teacher in the classroom. One way teachers must change is quite obvious. With the introduction of ICT into the classroom, teachers must learn how to apply these new technologies effectively in their efforts to improve their teaching as well as their students' learning. These changes are comprehensive and cover methodology, assessment, tracking, record keeping, communication, and curriculum evaluation. Teachers may also struggle with collaborative learning and sharing resources and working spaces. One of the most critical issues is the extent to which teachers will relinquish control so that their students can drive their own learning. Encouraging students to use computers gives them power to access, manipulate, modify, store, and retrieve information which ultimately gives them 
more autonomy in the classroom (Wheeler, 2001). While the implementation of ICT does encourage students to be constructors of new knowledge, Sutherland et al. (2004) stated that students still perceive their teacher as the knowledge provider simply because of the tradition of schooling. Regardless of students' perceptions however, there are times when a students' knowledge about using ICT technologies will exceed the teacher's knowledge. This can prove to be intimidating for teachers and cause them to fear the implementation of ICT in their classrooms. Yes, the role of the teacher will change, but Sutherland et al. (2004) argued that ICT does not simply change the role of the teacher from "teller" to "facilitator." They viewed the teacher's role as a gradual shifting of perspectives from the "more knowledgeable-other," to the "co-constructor of knowledge," to the "vicarious participant." In other words, sometimes the teacher's role is to lead the students, sometimes it is to interact and engage the students in conversation, and sometimes it is to remain silent.

According to Wheeler (2001), there are four main ways that the teachers' roles will change as they integrate ICT into their classrooms. First of all, because ICT will make some resources obsolete, teachers will need to employ electronic forms of distributed communication. Secondly, ICT will most likely make some forms of assessment redundant and unnecessary. Certain forms of traditional testing will eventually be replaced with computer-based assessments. Thirdly, as mentioned before, it will no longer be sufficient for teachers to merely impart knowledge. Teachers will be expected to encourage thinking skills, promote information literacy, and nurture collaborative working skills to prepare their students for the outside world of technology. 
Finally, teachers will need to move beyond the traditional linear method of teaching and design lessons with non-linear elements.

The use of technology in the classroom presents a need for a healthy balance between whole-class and individual/group work. With the implementation of ICT, it is often assumed that individual and group work will replace whole class work. Sutherland et al. (2004) argued that a balance between the two is a key aspect to successfully implementing ICT into school subjects. While using some forms of technology seem to be more suitable for individuals or small groups, the same technology can be used to benefit the whole class as the students use it to present what they have learned. The sharing of student work with the entire class is helping teachers and students to shift from individual knowledge to collective and shared knowledge.

The use of ICT brings up the issue of interactivity in the classroom. Kirkwood and Price (2005) claimed that ICT has been transforming the nature of long distance education for individual learners in various ways. ICT has introduced a new level of interaction that previously had been difficult to achieve. Software related to the subjects being taught can engage students with new learning activities across a wide range of disciplines. Furthermore, the Internet enables two-way communication to be enhanced, making dialogue not only possible with other pupils but with tutors as well. As the student body becomes more diverse, teachers at all levels of education (elementary to secondary and especially beyond) will need to be aware of their potential learners and their familiarity with ICT as well as their ability to access it from home.

Interactivity is a term that educators are familiar with, but it has many facets. In fact, Hargreaves et al. (2003) came up with 9 different types of interactive teaching 
constructs. As they interviewed teachers' perceptions concerning interactive teaching, they found that they offered several conceptualizations of interactive teaching especially in reference to different purposes and contexts. While ICT does encourage a sense of interactivity, Tanner and Jones (2007) saw the importance of considering the differences between technical interactivity, pedagogical interactivity, and conceptual interactivity. Technical interactivity simply refers to the student's interaction with ICT (i.e. manipulating text and images). Pedagogical interactivity and conceptual interactivity are more in-depth. Pedagogical interactivity is necessary for effective teaching while conceptual interactivity is essential for effective learning. Their study showed that ICT was popular among the students involved in their study, but their interest was mainly concerning the superficial features of the technology. Oftentimes, interaction in whole class settings is teacher dominated as the teacher asks questions and the students quickly give a response (Burns \& Myhill, 2004). The students that Tanner and Jones (2007) interviewed gave evidence that the quality of teacher-pupil interaction was the most important factor for significant learning. ICT alone did not contribute to pedagogical or conceptual interaction.

According to Venezky and Davis (as cited in Venezky, 2004), ICT rarely acts by itself as a catalyst for change in schools. In other words, simply implementing ICT in schools does not guarantee that schools will change their approaches to teaching or change some other major aspect of education. However, ICT can be a powerful lever for actually reaching planned educational innovations that were previously set goals. ICT has helped to reach goals that were essential for overall change, but it was not the cause for that change. ICT simply cannot be added to a particular educational situation and be 
expected to solve its problem. In order for ICT to be a lever for change, someone must first set a goal or a vision for change and then implement ICT in order to meet that goal. When used properly and efficiently, ICT can prove to be very powerful. With the use of ICT, schools can access a vast array of resources; form learning communities by connecting with families and teachers; give students opportunities to work outside of class from anywhere that they have Internet access; and bring in experts from around the world (Venezky, 2004).

Interactive Whiteboard

The interactive whiteboard (IWB) is a branch of ICT that has played a huge part in transforming today's classrooms. The IWB is large touch-sensitive board that controls a computer that is connected to a digital projector (Smith, Higgins, Wall, \& Miller, 2005). The IWB is sometimes referred to as an electronic whiteboard or SMART Board. In 1991, a pioneer company called SMART Technologies produced the first SMART Board interactive whiteboards. Since then, IWBs have a come a long way and many schools have these special whiteboards in their classrooms (SMART Technologies, 2006).

The IWB is a technological tool that has great potential. Smith et al. (2005) researched IWBs and came to the following conclusion: The IWB is not only a tool to enhance teaching, but it is also a tool to support learning. Beeland (2002) stated that the IWB is a tool for delivering instruction in a variety of ways that fall into one of three modalities of learning: visual learning, auditory learning, and tactile learning. The IWB helps students who are visual learners by providing them with a variety of visuals ranging from text and pictures to the use of animation and videos. Auditory learners also benefit 
from using the IWB through activities such as listening to sounds or music as part of a classroom presentation. Even tactile learners find the IWB helpful as they physically interact with the whiteboard by touching and moving things on the screen (Beeland, 2002).

Generally speaking, you can perform a variety of different functions with the IWB. For example, you can write, erase, and perform mouse functions with your finger, a pen or any other object that has a firm maneuverable surface. You can write in digital ink over websites and other applications. You can save your work or your notes and move them into a different software application. In the latest version of the IWB, you can even download software onto a personal computer. This is a great advantage for teachers because it allows them to create lessons from home. Furthermore, it allows students to review lessons and complete their work from home, provided that they have access to the Internet (Starkman, 2006).

Beyond the three different learning modalities that the IWB promotes, there is a variety of other more specific ways that the IWB can be used in the classroom setting. According to Reardon (2002), the IWB can be used to record class notes and homework assignments; prerecord a daily lesson; connect a whiteboard to a computer and the Internet; and integrate software programs into instruction. Ziolkowski (2004) surveyed some teachers in his local high school and found some creative ways that the teachers implemented the IWB in their classrooms. Ziolkowski used the "notebook feature" of the SMART Board to import images into his physics class. Other teachers made lessons ahead of time, saved them, and then used them repeatedly to demonstrate skills that the students needed to know and understand. A language arts teacher imbedded a variety of 
images, sound clips, and movie clips into his lessons, which were mostly downloaded from Internet searches. Gillen et al. (2008) researched the use of the IWB as a resource in a primary science classroom. They found that the teachers in their study used the IWB to present their objectives at the beginning of the lesson. Shenton and Pagett (2007) found that language arts teachers made pre-prepared screens so that they could scaffold and modify writing, using the IWB's tools to highlight texts in color and magnify them for closer perusal. Teachers also saved work only to return to it later and review it with their students. As previously mentioned, sometimes they also downloaded resources from the Internet to use with their lessons. Multimodal texts such as hyperlinks to other websites were commonly used as well. Villano (2006) found that teachers can manipulate a variety of tools that enables them to present slides, take notes, write in digital ink, control applications on a computer, and save work to share at a later time. Beyond the classroom, Fletcher (2006) stated that while teachers can use the IWB for demonstrations and introductions to specific units, they can also capture that same information and present it on their websites so that students can view it at their leisure.

The IWB is ever evolving. One of the emerging forms of the IWB is the wireless tablet. This portable wireless tablet functions similarly to the IWB. Wireless tablets allow teachers to stand at a distance from the IWB and yet control what is displayed on the whiteboard for the students to see (Landis, 2005).

The term "e-teaching" is a unique term used to describe the new pedagogy that is evolving with the use of the IWB. E-teaching involves the use of ICT to enhance the art of teaching students. E-teaching allows teachers to make use of a wide variety of resources through one simple piece of equipment - the IWB (Kent, 2006). 
Another emerging form of the IWB has proven to enhance the learning of deaf students as well as students with learning disabilities. Software called SynchronEyes has proven effective for deaf students. SynchronEyes allows a teacher to monitor each student's computer screen as well as disable the mouse and keyboard controls when the students should be looking forward to the front of the room. Teachers can also choose for certain messages to appear on the students' individual computer screens so they know when to stop working and look to the front of the room (Mackall, 2004).

Implementing the IWB

Implementing the IWB into the classroom setting will no doubt change the classroom culture. Glover and Miller (2007) researched the effects of implementing IWBs into all mathematic classrooms in secondary schools. After implementing this change, many other changes took place in these classrooms. Some of these changes included classroom organization; pupil-pupil interaction; teacher-pupil interaction; selection of software and other resources; the IWB as the focus for the activities; rapport between learners and the subject being taught; and pair, collaborative and group learning. According to these researchers, all of these changes appeared to generate a culture of learning within each classroom.

While implementing the IWB tends to change the classroom culture, it is just as true that the classroom culture plays a huge role in how well the IWB will be implemented into the daily routine of instruction. If the classroom culture is not supportive and fails to create an environment where both students and teachers feel safe to explore the IWB without fearing failure, successful implementation of the IWB will be hindered (Kennewell \& Beauchamp, 2007). According to Kent and Facer (2004), socio- 
culture theory brings the culture of human action to the front and center. One must first realize that both the teacher and the students work within a local classroom that is influenced by local, national and even global factors. It is within this context that the teacher and students bring their own personal history of experiences which relates specifically to their previous cultures of learning and tool use. Knowing this, it is not surprising that when a teacher or a student is faced with a new technology, both are prone to make sense of it in terms of their previous knowledge and experience of older technologies.

In order to use the IWB effectively, Glover and Miller (2007) made the following suggestions: the classroom should be arranged in a way that the equipment complements rather than intrudes upon the learning environment; the lesson should include stimulating software in a stepped learning process with plenty of opportunities for pupil activity; and the teacher should be demonstrative, embracing, and aware of all students so as to present a lesson that engages and captures the students' full attention.

Cox and Abbott's study (as cited in Kennewell \& Beauchamp, 2007) showed that when the IWB is effectively implemented, it carries a great opportunity to impact student learning. The key to effective implementation lies with the teacher, the pedagogical approach adopted, the ICT resources employed, and the learning objectives intended. Research has shown that the IWB can have a positive impact on learning. For example, the IWB engages students; promotes a longer attention span and better focus; provides visual and dynamic representations; improves student motivation; encourages the pace and flow of a lesson; and provides multimodality (Kennewell \& Beauchamp, 2007; Smith et al., 2005). Other positive results of using the IWB include differentiation; reflection; 
collaboration; and retention and transfer of knowledge learned (Kennewell \& Beauchamp, 2007).

If the IWB is properly implemented and perceived as more than a mere presentation tool, it can promote interaction in the classroom. The classroom teacher needs to recognize that the IWB can be used in this way and then use appropriate software that affords that positive interaction between teachers and students and between students and their classmates. An IWB can afford interactivity by encouraging students to make use of the different ways of manipulating the applications that are running on the screen. Interactivity can also be increased as students and teachers both interact with the IWB through the use of the keyboard, the electronic pens, or from digital control devices from other parts of the room (Armstrong et al., 2005).

Benefits of Using the IWB

The IWB is a unique piece of technology that allows both teachers and students to perform a variety of techniques as well as tap into a wealth of resources. Kennewell and Beauchamp (2007) found that teachers felt that the IWB was especially effective in gaining and then keeping their students' attention for longer periods of time. They also felt that the IWB's large display helped their students to focus on the content being taught rather than on the teacher or on their classmates. On a more practical level, teachers found the IWB to be a great advantage because it allowed them to make their resources and then save them for the actual lesson. Kennewell et al. (2008) also found that this technology made it easier for teachers to prepare material in advance, quickly retrieve it for classroom display, and then manipulate the items directly on the whiteboard. According to Kennewell and Beauchamp's (2007) study, teachers also felt that their 
students were more apt to get involved when they taught with the IWB. While at first it may have been overwhelming to develop lessons for the IWB, teachers found it much easier to navigate the IWB and prepare lessons over time as they had more opportunities to practice and familiarize themselves with this particular technology. Furthermore, by preparing and loading lessons in advance, teachers felt that the IWB helped to create a smoothness to their organizational activities and overall classroom management. Ultimately, the greatest benefit perceived by these teachers was the notable increase in the students' level of engagement in the lessons.

The IWB has a variety of features that makes teaching and learning more effective. For example, as primary teachers taught science lessons, they presented the vocabulary words on the IWB and then highlighted key terms in red to carry high-sensory modality and capture the students' attention. Another common feature implemented by these teachers was that of the 'block reveal' technique. This allowed the teacher to cover up parts of the IWB so that the students could only see parts of the information at a time. The 'block reveal' technique is a great way to manage the pace of the movement throughout the lesson (Gillen et al., 2007).

The IWB makes it possible for students to see not only what is portrayed on the IWB but also any changes or additions that are made with the electronic pens. The IWB is very similar to a chalkboard, but it carries the possibility of using color, images and even moving images. The IWB also makes it very easy for teachers to access a wide range of resources and materials to support instruction. Oftentimes the IWB is controlled by the teacher as she stands at the front of the classroom. However, there are handheld 
remote control devices available which allow the teacher to make changes on the IWB from anywhere in the room (Clyde, 2004).

According to Kelley, Underwood, Potter, Hunter, and Beveridge (2007), a genuine advantage of using the IWB is the ability of the teacher to face the class for longer periods of time for each lesson since PowerPoint and other software programs allowed the teachers to prepare a few extra visuals. Other benefits for using the IWB include the following: much clearer images and sounds; flexibility; and upward compatibility. Schweder et al. (2008) found that the IWB is also very mobile, making it more accommodating to students with special needs. The height of the IWB is easily adjusted so that it can accommodate those in wheelchairs or those who have other disabilities. Even students with hearing and visual losses are able to participate in various interactive whiteboard activities.

While the use of the IWB does not guarantee that a higher focus is being placed on learning, the benefits of the IWB do seem to support more effective teaching. For example, the IWB is reported to enable smooth transitions between activities; quicken the pace of the lesson; provide "seamless flow" from one teaching point to another; reduce the time spent on managing resources; and prepare the lesson for classroom presentation (Smith et al., 2005). Ultimately the IWB does add value to the classroom, but the value added focuses mainly on teaching more efficiently.

One of the major benefits of using the IWB is that this technology makes it extremely easy and convenient for educators to employ multiple modes of representation with one simple resource, the IWB. It could be argued that teachers could find the individual resources needed and implement them separately, but the IWB makes it 
possible to accomplish all of those goals with just one piece of technology. As teachers make wide use of the many different forms of representation on the IWB, students generally become more engaged in the lesson being taught. The IWB itself does not accomplish this feat. Teachers ultimately have to take advantage of their students' interests and then engage them multi-modally so that they can create cohesion and continuity that might not be achieved in a more traditional setting where there seems to be more of a disconnect between disparate events. According to Smith et al. (2005), some of the potential benefits of using the IWB include the following: flexibility, multimedia/multimodal presentations, efficiency, the ability to model ICT skills, interactivity and participation in lessons, and ease in the planning and the development of resources. The IWB also helps to quicken the pace of lessons. Less time is spent moving from one idea to the next when the IWB is implemented because such a plethora of resources are found in this one piece of technology.

The use of the IWB has the potential to increase interaction between teachers their pupils, but this interactivity depends on the skill of the teacher (Jones, 2004). According to Knight, Pennant, and Piggott (2004), the interactivity of the IWB comes more into play as teachers move down the following continuum of teaching contexts: 1) teacher as demonstrator, 2) teacher as modeler, 3) teacher in control, 4) pupils in control with the teacher advising, and 5) pupils working independently. Gillen et al. (2007) discussed classroom interactivity, but they made a distinction between technical interactivity and pedagogical interactivity. In terms of technical interactivity, the IWB seems to make a much smoother presentation from one technology to another. Pedagogical interactivity, on the other hand, is a little more complex. Teachers who use the IWB often find 
themselves standing at the front of the room near the whiteboard, which often means that the teacher is more apt to lead to a more traditional style of teaching. However, a truly effective teacher will use the IWB in order to produce a lively, varied and complex interactive lesson where the students are actively involved in the manipulation of information.

\section{Disadvantages and Limitations of the IWB}

As with any new technology, there are always disadvantages and limitations that hinder its use. One of the disadvantages of the IWB is that only one person can use the board at any given moment, which limits the amount of interaction that the teachers can have with their students at any particular time (Shenton \& Pagett, 2007). Another disadvantage from using the IWB is that oftentimes the student's active involvement with the IWB during whole-class instruction slows down the pace of the lesson and can cause boredom for the other students (Smith et al., 2005).

If the IWB is to be used effectively in the classroom, teachers must be properly trained and then provided with the necessary support to continue implementing the technology available at their fingertips. According to Freedman (as cited in Clyde, 2004), the IWB is often underused because teachers lack the time to find and develop resources and materials to use in the classroom. As Shenton and Pagett (2007) noted, practical issues such as technical support and installation of new equipment, could prove to be very troubling if these issues cannot be acknowledged in a reasonable fashion. In order for the IWB to make positive changes in today's classrooms, there is sufficient evidence that professional development support must be provided frequently (Glover \& Miller, 2007). 


\section{Teachers' and Students' Perceptions}

Glover and Miller (2003) studied teachers' attitudes towards the installation of IWBs in their classrooms. Their research showed a variety of attitudes/perceptions among the teachers chosen to be a part of the study. They classified the teachers' attitudes into one of the following categories: the missioners, the tentatives, The luddites, the revolutionaries, the gradualists, and the reactionaries. Each category consists of teachers with certain characteristics. For example, the "missioners" are those teachers who have already implemented the IWB into their lessons and who strive to get other teachers involved in that way. The "tentatives" are those who are interested in the IWB yet are fearful because of their lack of knowledge. The "luddites" are those teachers who have had trainings for how to use the IWB, but they are fearful of embarking on a new journey and putting forth the extra time and effort needed to use the IWB effectively. "Revolutionaries" believe that the IWB has value and they seek to find ways to get other teachers on board with them to use it effectively. "Gradualists" are teachers who are aware of the need to change, but they change slowly, over time. Finally, the "reactionaries" are those teachers who are fearful that the new technology would bring problems for the school so they use the current or potential resource problems as a means of deferring change. Based on this study, when administrators want to implement the IWB into their classrooms, they need to take into consideration the attitudes and perceptions of their teachers since the pace of change clearly rests in their willingness to jump on board and make the changes a possibility.

In a study conducted by Shenton and Pagett (2007), teachers' perceptions on the IWB were researched in six British primary classrooms. Many of these teachers saw the 
IWB as a powerful, extra resource to support their teaching. The IWB allowed them to be more creative with their lesson presentations. Furthermore, the IWB helped them with classroom organization and time management. Because the IWB is so versatile, the teachers could accomplish a variety of tasks without the distractions that often result when one has to stop and pass out papers or change to another form of technology. One teacher in particular felt that the IWB had the potential to lead to more "whole-class, teacher-led lessons." While most teachers felt that the IWB had great potential to engage students in the learning process, they did not deny the fact that there was always a tendency for them to dominate the IWB so that students were not as fully engaged with the IWB as they could have been had they had more of an opportunity to explore it on their own. The teachers also admitted that it took a considerable amount of time and effort to create materials to use with the IWB, especially for those teachers who were implementing this type of teaching for the first time. While teachers recognized that the IWB had a positive impact on students by motivating them to learn and stay focused, they also recognized that for some students, the IWB served as a distraction for them. These teachers then had the challenge of finding ways to help those students to stay focused.

Many of the students' perceptions of the IWB are similar to those of their teachers. For instance, Shenton and Pagett (2007) interviewed students from six primary classrooms in Britain. The students said that they liked the IWB because they could use it to view pictures from the Internet and watch video clips. In another study of British primary students, Hall and Higgins (2005) found that students liked the IWB because it had a wide range of resources that were versatile and easy to use. They also seemed to enjoy the multi-media capabilities of the technology and claimed that these elements 
helped to gain and hold their attention during the class lessons. For example, the students were very interested in the visual aspects (color and movement) as well as the audio aspects (sounds and videos). The students interviewed in this study also commented that the IWB made learning more fun and enjoyable. While these students' perceptions of the IWB were generally positive, they also shared what they did not like about the IWB. Some of the problems perceived by students included failings of the technology itself (i.e. the IWB "freezing up" or shutting down and the sunlight shining on the IWB, creating a glare on the screen). Another common perceived problem among the students interviewed was the need to reorient the board. Students also complained that the IWB is sometimes fuzzy and difficult to read. Finally, students expressed their desire to use the IWB more in the classroom if possible.

Wall et al. (2005) conducted a study in English primary classrooms to research students' perceptions of the IWB in the classroom. Overall, the students claimed that the IWB assisted their understanding and learning and motivated them to engage in the lesson because of their desire to use the IWB personally. In regards to their teachers, the students in this study claimed that the IWB not only helped their teacher to explain certain concepts, but it also helped them to become more enthusiastic and innovative in their teaching. When asked to share some of the disadvantages of using the IWB, the students mainly focused on the technical reliability of the whiteboard and the associated equipment. Another negative comment repeated frequently was the need for reorienting the board in the middle of a lesson. Students also complained about waiting for the technology to start up. 
Students with learning disabilities also prefer using the IWB. According to Mechling, Gast, \& Thompson (2008), students who were interviewed said that they liked the IWB because they could see the words, it was easy, and it was fun.

\section{Summary}

With the rising use of IWBs in today's primary classrooms, it is imperative to assess its effectiveness and value. The many uses of the IWB as well as the benefits and barriers to implementing the IWB into the classroom setting have been researched by a number of educators (Fletcher, 2006; Landis, 2005, Reardon, 2002; Starkman, 2006; Ziolkowski, 2004). However, even fewer studies have been conducted to investigate students' perceptions of the IWB and the effect it has on them. Those studies that have been conducted to research students' perspectives of the IWB have been in British classrooms (Hall \& Higgins, 2005; Wall et al., 2005). There is a need to explore the question of how students perceive the IWB at the primary level (specifically third grade) in a regular education classroom in the United States.

In addition to researching the general effects of technology (specifically the IWB) on education, it is also important to research the effects in a specific subject area. Research has been performed on using technology in science, math and other content areas, but these researchers did not study students' perceptions (Knight et al., 2004; Jones, 2004; Ozel, 2008; Schweder et al., 2008). On the other hand, some research has been performed to determine students' perceptions of the IWB in specific content areas, but the studies were either conducted in a foreign country or in secondary classrooms (Hall \& Higgins, 2005; Mechling et al., 2008; Merrett \& Edwards, 2005; Wall et al., 
2005). Therefore this study focused on determining students' perceptions of the IWB in a third grade classroom, specifically during math instruction. 


\section{CHAPTER 3: METHODOLOGY}

For this project, action research was performed using a qualitative protocol. The goal was to assess students' perceptions of the interactive whiteboard (IWB) in the regular classroom setting. In order to achieve this goal, I taught my third grade class on an $\mathrm{ABAB}$ design. During the first phase, $\mathrm{A}$, I used the IWB in my teaching. Then during the second phase, I taught in the traditional manner. The alternating design provided for a comparison of students' reflections with and without the IWB. The entire study lasted eight weeks, with each phase lasting two weeks. The following pattern was established:

2 weeks IWB/ 2 weeks no IWB/ 2 weeks IWB/ 2 weeks no IWB

Dates of Phases:

Oct. 20, 2008- Oct. 31, 2008

10 days

Nov. 3, 2008 - Nov. 14, 2008

9 days

Nov. 17, 2008 - Nov. 28, 2008

8 days

Dec. 3, 2008 - Dec. 12, 2008

8 days

Even though I teach every subject to my third graders, this study researched my students' perceptions of the IWB in math class only. With the exception of special circumstances (holidays or special presentations), math class occurred daily for 1 hour. The lessons covered during the eight-week period included a variety of topics. During 
the weeks that I implemented the IWB in my lessons, I used PowerPoint, animations and occasional Internet sites to enhance the visuals that I used as well as to further engage my students in learning. When I taught without the IWB, I used the overhead, the chalkboard, and posters to supplement as visuals.

During this eight-week study, my students wrote in their personal journals at least three times per week to describe their experiences in regards to the technology that was or was not used in that particular lesson. At the end of the eight weeks, the students were interviewed and asked to share their perceived benefits and limitations of the IWB. I also asked the students to share any ideas that they might have for improvement in the IWB's usage in the classroom.

\section{Rationale for the Method}

Action research is a common method of research used by educators because it is a practical problem-solving approach. Furthermore, the results of the research often provide very useful information to improve education in a specific way. The educational issue that I chose to focus on was student perceptions of the IWB in the classroom setting. This information was gained by assessing students' perceptions through journal entries and personal interviews, and the results were able to inform other third grade teachers (and elementary teachers in general) about future uses of the IWB in the regular education classroom.

As formerly mentioned, a dearth of research has been conducted on students' perceptions of IWB's, especially at the elementary level in the United States. Therefore, I proposed to ask a question to know how students perceive the use of IWB in their

classroom experiences. More specifically, I chose to explore how students perceived the 
use of the IWB specifically in math class. This goal was best met through qualitative research via students' personal journal entries and interviews.

Population of the Study

The population of the study consisted of third grade students. Particularly, the results have some small degree of external validity for rural, elementary public third grade students. The results of the study are most applicable to Caucasian students in the Northeast and of average socioeconomic status.

Sample

Sample Criteria. The participants used in this study were the students assigned to me by normal scheduling at the end of the previous school year. I collected data from 19 out of 20 students in my class, with the exception being one autistic student who is in a Life Skills class $90 \%$ of each school day.

Rationale for sample. I used my third grade students because that is the most realistic population for this study. As an elementary teacher, it would not be conducive to the learning environment to achieve a random assignment of students due to the nature of the elementary setting. Since I only studied my third grade students, I collected data on all but one student to attain a reasonable $n$ of 19 students. The total number of students achieved enough data collection for the study's intended purposes.

Methods of sampling. Sampling from the population occurred through class assignment which was determined at the end of the previous school year by the second grade teachers. No sampling occurred in the data collection process since data was collected from all of my students. Overall, my classroom comprised a sample from all rural, public, northeast elementary school students. 
Procedure

Instruments. The instruments used for data collection involved student journals and interviews. The student journal prompts were given to students and were the same each day. Following were the prompts:

1. What tools did your teacher use to teach the math lesson today?

Benefits:

2. If the IWB (SMART Board) was used today, how was it helpful? Explain. If the IWB (SMART Board) was not used, what types of visuals were used, and how were they helpful?

\section{Limitations:}

3. In regards to technology, what do you not like or what was not helpful about today's class?

Improvement:

4. How could technology have been used more effectively? What could be done to make it better?

Interview questions were prepared beforehand around the major constructs of benefits, limitations, and improvements (Appendix A).

Data collection methods. Two main types of data collection occurred throughout the course of this study: journals and interviews. First, students wrote in their personal journals at least three times per week. The students kept their journals in their desks during the week. The journal prompts were typed and located in the front of each student's journal. The journal prompts were also displayed on the IWB for the students 
to refer to. Students dated each journal entry and responded to the prompts each time they wrote in their journal.

The second set of data consisted of semi-structured interviews that I conducted with each student at the end of the eight-week period (Appendix A). I attempted to complete all of the interviews after the students returned from Christmas break. Each interview lasted approximately 10-15 minutes.

Relevant ethical considerations. This action research posed no harm to the participants involved. I taught math class in a normal manner. The only difference was that I was using the IWB in order to measure the students' perceptions of benefits and limitations of the IWB in the classroom setting. Since the students involved were minors, I attained written informed consent from the students' parents (Appendix B). The parents/guardians granted permission for their child to participate in a personal interview and have it recorded and transcribed. Parents and students both were informed that confidentiality would be kept throughout the entire study. I was the only one who knew their identity. All names used in the write-up were pseudonyms.

Treatment variable. The treatment variable was the use of the IWB. This was manipulated in my third grade classroom. The assessed variables were the students' perceived benefits and limitations of the IWB. Any areas that the students noted for improvement were also noted.

Methods of data analysis. All of the journal entries written by the students were organized by date. At the end of every week, I collected the students' journals and recorded their responses in a table as a word document in order to make it easier to 
compare entries and look for common themes and constructs. Each personal interview was transcribed and organized according to each particular question.

Data analysis involved coding, which involved assigning category names to different groups of data. The first round of coding occurred by comparing reoccurring themes or constructs throughout the data (journal entries and initial interviews). In doing this, I added emerging codes and removed other codes that were rare. This resulted in a master list of codes. Finally, I assessed the data for those particular codes and imbedded themes that emerged from the data. 


\section{CHAPTER 4: QUALITATIVE ANALYSIS}

This study analyzed students' perceptions of the IWB's use in a third grade classroom. During the weeks that the IWB was implemented, I often constructed PowerPoints to enhance the lesson. These PowerPoints often included a variety of pictures and animations to display the lesson objectives. Many of the math lessons were pre-designed and saved on the SMART Notebook feature. These lesson pages included pictures, graphs, and other visual resources offered by the SMART Notebook gallery. For some lessons, I used the Internet to further explain a particular math concept. During the weeks that the overhead/chalkboard were being implemented, the objectives for the math lesson were usually stated verbally, and the math concepts that needed to be demonstrated were done so mainly on the chalkboard. For various lessons, the math curriculum provided posters to display certain information (i.e. graphs and charts). Flashcards and manipulatives were sometimes used as well.

It is important to note that the math curriculum I used during this project also included something called math meeting. Math meeting is a daily math review that takes place every morning from 9:00-9:30. As the students arrived in the morning, they found their seats and completed the math review problems (i.e. telling time, counting money, writing number sentences, completing number patterns, answering story problems, etc.) that were displayed in one of two ways. When I was using the IWB, all of the math questions were displayed on one page of the SMART Notebook. Then when it was time to go over the answers, the student of the day would lead the class through each problem 
on the IWB. (Each problem was displayed on a separate page of the SMART Notebook so that the students had ample room to write as they showed their work. These pages could also be revisited at a later time if a student had a question about a particular problem.) When I conducted the math meeting without the IWB, the problems that the students needed to solve were displayed on posters that were hanging on the chalkboard. As we reviewed each problem, the students wrote their answers and displayed their work either on the posters or the chalkboard.

The overhead projector was used daily during all sessions to complete side A of the students' homework papers. This was held constant throughout the entire study. When the students' journaled about their experiences, they were to reflect on the day's lesson or the day's math meeting and how it was taught (i.e. with the overhead/chalkboard or with the IWB).

Analyzing the students' perceptions of the IWB versus the overhead/chalkboard revealed great educational benefits for the IWB's implementation in daily instruction. I found that the IWB increased the interest level of my students and engaged them in the learning process. Furthermore, I found that the IWB enhanced overall instruction in the classroom. The instruction was perceived as improved by offering more visuals and using more color. Not only did the students share the benefits of the IWB's use, but they also shared areas of concern as well. Some of the limitations they described included reorienting the board, dealing with computer problems, and experiencing writing difficulties. Finally, the students mentioned areas for improvement in the IWB's use. Some of their ideas included using more color, incorporating more animations, designing more PowerPoints, and increasing student interaction with the IWB. 
It is important to note that the students in this study often referred to the IWB as the SMART Board. Prior to this study, the students did not know that the SMART Board was a type of IWB (interactive whiteboard). Consequently, the students' journal entries and their statements from their personal interviews often referred to the IWB as the SMART Board. For the sake of this study, the terms "SMART Board" and "IWB" will be used interchangeably.

\section{Description of the Data}

To measure the students' continued perceptions of the IWB in my third grade math class, they wrote in their journals at least three times per week for the entire eight weeks of the study. This included responding to the four journal prompts each day regarding the particular technologies that were implemented. The questions were organized around the three constructs of benefits, limitations, and improvements. Interviews were also conducted at the end of the eight week study. Each interview lasted approximately 10-15 minutes and was tape recorded and transcribed for later analysis. Through constant comparison of the transcribed data and journal entries, several themes emerged. These themes will be explained in the remaining pages of this chapter. Interesting Aspects of the IWB

Engaging. Students clearly expressed that the IWB was more engaging than the overhead or the chalkboard. Many students claimed that the IWB was more interesting and it kept their attention longer. After two weeks of not using the IWB in math class, James wrote the following in his journal entry: "I liked when we got back to the SMART Board." On that same day, Nathan wrote: "I like the IWB better," and Brice wrote: "I like to be back on the SMART Board." When not implementing the IWB in the 
classroom, students expressed their desire to use the IWB in their journal entries. Nathan noted: "I would like to use the IWB and PowerPoint. I hate the chalkboard."

When asked to compare their excitement level in class when using the IWB versus the overhead/chalkboard, the students favored using the IWB. One of the key reasons that the students preferred the IWB was because it was fun. For example, Emily said that she liked "the SMART Board cause you usually have more funner things to do with it." In a journal entry, Sarah wrote this about the IWB: "It is easy to work with. It is fun." Similarly, Rachel wrote: "I like the IWB because it was fun." Catherine noted: "Yes, it was helpful because I like drawing on it. And it was very fun."

Another reason the students preferred the IWB was because of the variety of presentational tools that were used. For example, when making the lessons on the SMART Notebook, I often used a variety of colors for the text. I also varied the background colors for different lessons. I frequently included pictures and animations to help capture the students' attention. When asked to compare her excitement level when using the IWB to the overhead/chalkboard, Rachel stated that she liked the IWB "because you can do a lot of different stuff on it ... and on the other one you can't do it that much." When using the IWB for instruction, I also made PowerPoint presentations for each lesson in order to display the lesson objectives in a creative way. The PowerPoints included animated objects and often included sound effects. When asked to think of a specific time when the IWB changed the student's interest level in the lesson being taught, Caleb said: "You had a bunch of PowerPoints in it and that really caught my attention." Other students felt the same way. Brice stated: "It caught my attention by...those pictures you put up. It gets my attention because when it has sound, I can hear 
it. And if I'm talking or something, I'll look over and I'd see it or hear it or something and that would warn me that it's on." When comparing the IWB to the overhead/chalkboard, Tim stated: "Something really cool on that IWB is that you can do a PowerPoint on it, and see that is very fun. That's why I like it." Students further reflected their excitement over the mini PowerPoint presentations in each lesson as they wrote in their daily journals. For example, Catherine penned: "I also liked the PowerPoint. When she got the pictures that helped me to focus." Sarah echoed Catherine's excitement over the PowerPoint presentations when she wrote: "I liked the PowerPoint. It was awesome!" Rachel liked "when the words popped up." Rachel's comment was in reference to the lesson objectives that were on each PowerPoint presentation. I often added animation to the presentations so that the objectives were not stationary. They often entered in a variety of motions in order to capture the student's attention.

Along with using different methods of presentations, the students also seemed to place a high value on the visual aspects of the lesson. In other words, the students had a high appreciation for color and the presence of pictures and shapes that could easily be maneuvered with the touch of a finger on the IWB screen. When asked to compare the IWB to the overhead/chalkboard, Tim stated: "I like it because we can go up there and write with different colors and there's some cool things you can press and something cool happens."

For many of my lessons, I would include various pictures or other colorful visuals. In one particular lesson on comparing numbers using the following comparison symbols $(<,>$, and $=)$, I included a picture of a huge crocodile on each page of the 
SMART Notebook. The crocodile was a visual reminder to my students that just as a hungry crocodile would always choose the bigger amount to eat if given a choice, the "mouth" of the comparison symbol that the students placed between two numbers must always face the greater number. This really captured the students' attention and seemed to help them understand this concept in a more meaningful way. In their journals that day, several students expressed how they liked the pictures. For some students, the pictures seemed to serve more as an attention getter. For others, however, the pictures seemed to help them learn. James wrote: "I liked the alligators." Charity wrote: "I liked the big problems. I like the way you taught us the alligator way with the mouth opened to the bigger number. That will make me remember." Caleb commented: "I liked the crocodile math. That really helped me pay attention.”

The students conveyed their interest in watching me create different shapes, pictures, diagrams, and other visuals right before there eyes as the lesson was being taught. Oftentimes, during lessons I used the creative pens on the SMART Notebook feature. These pens allowed me to draw attention to something on the board that I wanted the students to pay particular attention to. Many times I would highlight important information with a yellow highlighter. I often created "perfect" shapes by using the tool drop down menu. I could easily color these shapes with the touch a finger and the students would be captivated by these "magic" moments. When asked if she preferred the IWB or the overhead/chalkboard, Catherine said that she preferred the IWB because "you can go on SMART Board and make these cool designs without making mistakes. And if you make a mistake, you don't have to erase everything. You can just hit delete and that's it." Other students agreed with Catherine and preferred the IWB 
because of the variety it offers. For example, Laura stated that she preferred "the IWB because you can make different colors and different shapes and different stuff on it." When asked which he would prefer, Raymond stated: "The IWB cause it has all kinds of different stuff on it like different colors and different like shapes and uh you can like put stuff like a chart on it."

\section{Improved Instruction}

Improved visuals. Compared to the overhead/chalkboard, many students shared that the IWB was easier to read and to see. When Rachel was asked to compare the IWB with the overhead/chalkboard, she stated: "The interactive whiteboard, that one you can see better. And the chalkboard, I can't see that well.” Tim stated: “The IWB makes big letters so I can see better." Sarah also gave evidence that the IWB is easier to see when she said: "Cause you can see it because it's like up high. And you can see wherever you are and its really big and not small, like on the chalkboard." Laura echoed this sentiment by saying "On the SMART Board you can see stuff a little better. The overhead it's kind of smudged." Furthermore, in a journal entry during IWB instruction, Catherine wrote, "It was easy to read."

One of the reasons the students perceived that the IWB was easier to see was because of the efficiency of the IWB in regards to erasing the board. In comparison to the overhead, Raymond said, "The IWB can um erase easily and the overhead projector, you have to put water on a paper towel and wipe it off." Tim stated: "I can really see it better than the overhead projector. It's very easy to get that stuff off, but ... with that (the overhead projector), you have to use a little wet towel with a wet kind of towel which actually is um hard." Similarly, when comparing the IWB to the chalkboard, Daniel said 
that the IWB "has better erasing than the chalkboard, and when you erase, it doesn't leave a big whole mess." Sarah expressed frustration when using the chalkboard when she stated: "On the chalkboard it's hard because you have to erase it and you can still see the marks." Caleb said that he preferred using the IWB because "you can see it much better and you can do things much better. It's much more easier to erase."

Increased Interaction. Another interesting element that the students appreciated about the IWB was the ability to interact with this newer form of technology. The students expressed their desire to write on the IWB. Shelley stated: "I like never used one before and like my teachers in the past ....they only got to use it. And in your class we get to uh write the answers on the board." Stephanie commented: "I really would like to draw on it um for math. And because I know that everyone else would like to. I just wish that I could." In their journal entries the students also conveyed their desire to write on the IWB. James wrote: "The IWB was helpful because we could write on it." Abigail wrote: "I like when I got to write on the SMART Board. It was the best when I got to write on the SMART Board." Caleb penned: "I liked to write on the IWB." During journal time, the students were always given opportunity to share ideas for improvement, and several students wrote that they would prefer to write on the IWB more often. Brice thought the lesson could be improved "if she let's us write on it more." Caleb wrote that the lesson would be better "if every person would get a turn." James wrote: "I wish we could go to the SMART Board more."

Along with writing on the IWB, the students also expressed their desire to move objects or words on the IWB's screen. In the "crocodile" comparing numbers lesson mentioned earlier, the students were given the opportunity to come up to the IWB and 
choose the correct symbol and drag it into the circle between the two numbers being compared. Several students commented about this in their journals that day. In her journal, Sarah wrote: "I liked that I got to move the arrows. It was fun." Shelley wrote: "I liked the IWB because we could put the symbols where we think it goes!" Catherine wrote: "It was helpful for me to go up to the board a lot." Brice penned: "I liked to move things on the SMART Board." Abigail shared: "I liked when we got to write on the SMART Board, and I like when we got to go up and got to move stuff with our fingers up on the SMART Board every day." Rachel wrote: "I liked when we had to go up there and move the numbers and the letters." After using the IWB for two weeks, the students experienced their math lessons with only the aid of the overhead/chalkboard or posters. In his journal, Brice wrote: "I like how on the SMART Board you can move stuff up but on the chalkboard you can't move stuff like letters or numbers."

\section{Enhancing Instruction}

Limitations. As with any type of educational technology or teaching tool, there will always be limitations. To assess the limitations of the IWB in the classroom, the students were asked to share what they did not like about the IWB, as well as to share any noted problems or things that they found to be distracting. One of the common themes included the basic technological problems that frequently arise any time computers are being used. For instance, when we used the IWB for a prolonged period of time, the projector would sometimes overheat and shut off in the middle of a lesson. Sometimes a little message would pop up on the screen saying that the projector was overheating. This gave us a mini warning that the screen would be shutting down soon, giving us several minutes to finish what we were doing on the IWB. When asked to explain any problems 
that happened with the IWB, the students were quick to mention this. Charity said: "The overhead projector overheats. Sometimes it gets overheated and you have to hurry to get everything done." Tim echoed her frustration when he said: "When it overheats, you have to turn it off...I would just like the IWB to stay on and not overheat.” Raymond said: "It can get really warm and you can't really use it." While many students noted that this was a common problem, several students shared that it wasn't a problem that occurred frequently. For instance, Charles stated: "Sometimes it shuts off," and Rachel said: "It turned off once." Laura went on to say: "It almost shut off once and one time we couldn't get it to really work, and one time we couldn't get it to come up. Like we couldn't get it to start." After the projector had turned off, it would take a while for it to turn back on. Shelley expressed her frustration with this when she wrote: "I do not like that it can take too long to turn on."

Students also noted that there were times when the cords to the computer and/or projector would get loose, thereby causing the green light on the IWB board to turn to red. (The red light indicated that a cord was loose somewhere. As long as the red light was on, no actions could be taken on the interactive whiteboard.) Sometimes it would take several tries to figure out which cord was loose. Stephanie explained her frustration with this by saying: "When the light's red, you can barely even figure it out." Sarah said: "Sometimes the cords get loose and then we have to take the time to fix it and then you have to figure out which way the cords go. So then it takes a long time to fix it."

Several students shared that it was difficult for them to reach the IWB. However, this problem could be eliminated by simply remounting the IWB in a different location. Regardless, this was a concern for some students. For example, Sarah said: "In some 
ways it's hard because I can't reach. It's hard for me to reach for some questions so I have to stand really high on my tippy toes so it gets really hard to do it on the IWB." Shelley echoed Stephanie's concern when she said: "Sometimes for small people, it's hard to reach it on top." Caleb also stated: "Sometimes I really can't reach some part of the IWB. Like if there's a problem at the top, then I can't really reach. It's hard." Another common problem perceived by the students included realigning the IWB. Because the projector sits on a movable cart, any time it is bumped, the projector could possibly move. Even if the projector gets bumped just a little bit, the board needs to be reoriented so that when a person uses one of the four pens, the writing will appear on the IWB where it is supposed to appear. Charity stated: "Sometimes if you forget to orient it whenever I'm writing up there, it doesn't work right." Stephanie said, “The only problem when some people bump it and you have to orient it. Because sometimes you forget to orient it and once you are done orienting it, sometimes in the morning you have to do it again." In a journal entry, Shelley wrote: "When the IWB is not oriented, you mess up a lot."

Students also expressed that some limitations were evident with the four colored pens on the IWB. Many students were frustrated that only one student could use the pens at any given time. Students often mentioned this limitation in their journal entries. For example, after returning to the IWB from the chalkboard/overhead, Emily wrote: "I don't like how you have to go one at a time to the SMART Board." Sarah echoed her disappointment when she wrote: "I don't like that you can't write two people on it." Several students mentioned similar things in the interviews. Catherine stated: "It's kind of difficult because um whenever two people use um use the IWB, you both can't write 
on it." Shelley said that the IWB was difficult to use because "you can't use the pens at the same time." Another common frustration involved the difficulty of writing with the pens on the IWB. Writing on the IWB by itself was not difficult. However, the students expressed frustration because if they accidentally touched the IWB as they were trying to write with one of the pens, stray marks and "wild lines" would show up on the screen. In their journal entries, the students articulated their annoyance with the pens at times like these. For instance, James wrote: "I liked when we got back to the SMART Board, but sometimes when you're writing, wild lines show up and makes your letters look funny." In the interviews, Brice stated: "You can't put your wrist on that cause it will draw with your wrist on the SMART Board."

Another limitation perceived by several students was the difficulty of moving/dragging things on the IWB. After a math lesson where the students were to drag numbers to different locations on the IWB, James noted: "The numbers were hard to move." In her journal, Sarah also wrote: "I did not like it when I couldn’t move it." Raymond penned, "It was not helpful because for some of us it was hard to move the stuff." When the students were having difficulty dragging objects on the IWB, I encouraged them to use their fingernail instead of their actual finger. This seemed to help them. For example, James stated: "Well, it was kind of hard to move the numbers until you start using your fingernail from side to side."

Other limitations were mentioned in the students' journal entries or in their individual interviews. Some students found the IWB to be blurry at times. Catherine wrote: "It was a little blurry because I'm so close to the SMART Board." After one particular lesson, Laura wrote: "It was blurry." Some students also stated that the IWB 
was sometimes distracting to them. For example, Catherine wrote: "On the chalkboard, it was helpful because it was easier to understand cause there were no colors and the colors on the IWB got me sidetracked."

Improvements. When questioned concerning possible improvements in regards to the IWB's use in the classroom, most students mentioned increased interaction, more visuals, and more PowerPoint presentations. The students really enjoyed interacting with the IWB and expressed their desire to use it more often in their journals. Catherine wrote: "It would be more helpful if we could go up to the SMART Board and touch the money so we could find the answer." When writing ideas for improvement in her journal, Emily wrote that the lesson would be better "if we could go up and write down the answers on the board." Emily wrote that she would like lessons better "if you can make enough for all of us," and Caleb wrote "if everyone would get a turn." James shared his desire to interact with the IWB more when he wrote: "I wish we could go to the SMART Board more."

The students really appreciated pictures and variety in color in the PowerPoints and IWB lessons that were on the SMART Notebook. Several students expressed their desire for more color and more pictures in their journals. For example, Charity wrote: “Animal pictures would wake me up. Colors would be nice!" In the interviews, Sarah stated: "You could draw more pictures and pull out more pictures on the IWB."

The students really enjoyed the PowerPoint presentations and requested more of these in the future. In her journal, Charity asked: "Could you use the PowerPoint more because it says and explains a lot of it and really helps me learn it?" Along with the PowerPoints, the students wanted to have more sound effects to go along with the 
pictures. Emily wrote: "When you do the PowerPoint, can you make it so that it has noise?" James stated: “Always keep sound effects on the PowerPoints.”

Along with PowerPoint presentations, many students thought that it would be helpful if there were more videos or movies to explain the math concepts being taught. For example, when journaling ideas for improvement, Christopher wrote: "Show a movie on the SMART Board." Shelley also wrote: "You could use video clips."

\section{Summary}

In summary, this study offered insight into the students' perceptions of the IWB in my third grade classroom. The perceived benefits of the IWB included engaging lessons, improved visuals, and increased interaction. While there were a number of perceived limitations, the students didn't see them as major disturbances as they clearly preferred the IWB over the chalkboard/overhead for instruction. Students gave some ideas for improvement which centered mainly on increasing the use of visuals and PowerPoint presentations, as well as providing even more opportunities for interaction with the IWB. 


\section{CHAPTER 5: DISCUSSION AND IMPLICATIONS}

After analyzing the results of this project, it is obvious that the IWB can be a valuable educational asset in the primary classroom setting. The variety of benefits that the IWB can bring to the classroom include heightening student engagement, increasing student interaction, enhancing visuals and presentations, and improving instruction. The limitations and disadvantages perceived by the students in this study proved to be few, infrequent, or minor in comparison with the perceived benefits of the IWB. This statement can be supported by the students' overall preference to use the IWB in class, rather than the overhead or chalkboard.

Interpretation of the Results

Drew on the technological interests of the students. It is obvious that we presently live in a culture that is inundated with visual images and technological advances of all sorts. Children are visually stimulated and often have great hand-eye coordination as a result of the many video games and computer programs that they play in their free moments at home. Students' love for new technology was clearly reflected in their journal entries and interviews. The students often referred to their desire to draw on the IWB or do "cool stuff" like making shapes and dragging things from one place to another. Stephanie said: "The reason I like the SMART Board is because I wish I had one at my own house...I love it because I like to draw on it. And I would really like to make pictures on it for everyone." Almost all of the students mentioned their desire to write on the IWB, and just as many mentioned how they enjoyed the PowerPoints, 
animations, and sound effects that were included in the lessons on the IWB. Knowing that students are intrigued by these new technologies is a huge asset to teachers as they use this information to their advantage by creating visually stimulating and highly interactive lessons that will engage their students in the lesson.

Increased enjoyment and higher motivation of students during instruction time.

The IWB was also found to increase the student's enjoyment of the lessons taught as well as to increase the students' interest level during instruction time. Almost all of the students in this study preferred to use the IWB rather than the overhead/chalkboard, which points to the positive impact that the IWB has on education. The students claimed that the IWB made the lessons more fun. Some said that the IWB was easy to work with and that it helped to catch their attention. More specifically, the students shared that the pictures and animations not only captured their attention, but they also helped them to focus on the lesson and learn new concepts.

Increased Interaction. The IWB increased the students' desire to interact with the IWB as well as with their teacher during instruction time. Students commented in their journals as well as in their interviews that they wished they could "go to the SMART Board more," or that they would like to "write on the IWB." The students seemed to be more engaged in the lessons when the IWB was being implemented, and they were more eager to raise their hands and participate. While their desire to interact with the IWB may have been superficial at times, their eagerness to participate was definitely a perceived benefit. As the students continue to participate, they will eventually become stronger academically, regardless of the reasons they have chosen to take part in the lesson. 
Improved teacher instruction. The IWB not only helped students to understand news concepts, but it also improved teacher instruction. The students in this study perceived that the teacher's lessons were more organized with the IWB. For instance, by implementing the SMART Notebook feature for the math lessons and math meetings, the teacher could move from one page to the next and revisit any particular page if a particular concept or problem needed to be revisited. The students also perceived that the IWB aided in designing and saving lessons that could be used at a later time. For instance, in Charity's words: "When you write something and then you want to save it, you don't have to erase it....you can keep it." The students also appreciated the use of PowerPoint presentations at the beginning of each lesson. They appreciated the pictures and animations that were included on these presentations and they looked forward to discovering what they were going to learn that day as the objectives for the lesson made their entrance on the PowerPoint. The students valued the variety of colors and the various tools that the teacher used in order to draw attention to important details. For example, the teacher often used different colored pens, as well as the creative pens that made unique shapes and/or served as a highlighter to emphasize important information. The students also noted that the IWB was easier to see for the following reasons: the IWB was brighter and clearer than the overhead/chalkboard; handwritten words on the IWB could be automatically changed into a particular type font that could easily be read by all students; words on the IWB could be selected and then made bigger simply by dragging the corner of the box that surrounds it; and the IWB could be erased more efficiently and neatly than the overhead/chalkboard. 
Beneficial educational tool. Based on the information gathered from this study, the benefits of using the IWB seemed to override any of the limitations mentioned by the students. Overall, the IWB appeared to offer many benefits to the educator who wants to bring out the greatest potential in each of his/her students. The problems perceived by the students were minimal and many of them can be remedied by making certain adjustments or taking steps to get the proper technological training or support. For example, the common problem of misalignment can be diminished by mounting the IWB on a wall rather than on a moveable stand. Furthermore, the projector and computer can be mounted on an immoveable structure, thereby eliminating the possibility of either of them being bumped and causing the IWB to need to be reoriented.

Other limitations mentioned by the students can be minimized by taking measures that are fairly easy and cost-efficient. For example, several students mentioned that the projector sometimes overheated and shut down in the middle of a lesson. To prevent this from happening, the teacher should make sure that the projector is turned off whenever the IWB is not in use.

A number of students perceived that the cords hooking up to the computer and projector could be a hazard if people tripped over them. This problem can be eliminated by safely covering the cords or by mounting the projector overhead. A similar problem noted by several students was the difficulty in reaching the IWB. Once again this problem can be reduced by mounting the board in a position that will be accessible by all students.

Finally, some students stated that it was sometimes difficult for them to write with the pens or to drag objects using their finger. Difficulties like these can be overcome 
with proper training and practice. The more opportunities that the students are given to use the IWB, the more efficient they will become at performing these particular tasks. Potential Application of the Findings

Consider the set up for the IWB to allow for maximum benefits. As previously mentioned, based on the present study, it is of utmost importance to consider the set up for the IWB so that both the teacher and students can experience the maximum benefits of the IWB. If possible, the IWB should be permanently mounted on a wall that can be seen easily from each student's desk. The board should be mounted at a height that is appropriate for the age group of the students who will be using the IWB. If the projector and computer can be mounted permanently, that is the best option. However, if this cannot be achieved, care should be taken to place the projector and computer on a cart or immovable structure that will not obscure the students' view of the IWB. Teachers need to make sure that the cords are properly covered or that the cords are not in a highly trafficked area. By taking these measures, teachers will minimize the possibility of student injuries due to tripping over the cords.

Invest sufficient time and resources. As with any new technology, it is vital to invest time and money to ensure proper training for teachers so that they know how to properly use the IWB. Teachers need to be familiar with the IWB in order to create lessons that they can use in their classroom to increase interaction and motivate students to engage in the learning process. Oftentimes, teachers are fearful of trying new technology because they lack the support that they need to help them when they find themselves in a difficult situation. Schools who desire to implement the IWB should seriously consider making provision to incorporate several training sessions during in- 
service days. Furthermore, school administrators might find it advantageous to provide extra training for those teachers who are especially eager to implement the IWB in the classroom. These teachers are often more than willing to share their innovative ideas, and their enthusiasm is contagious. Having several teachers like this throughout a school building will greatly increase the possibilities of the IWB being adopted by teachers who are often more hesitant towards change, especially in the area of technology.

Devote time and effort to organize and present lessons. Ultimately, teachers must be willing to invest their own time into implementing the IWB and preparing lessons. In the present study, the teacher spent a great amount of time preparing lessons on SMART Notebook and preparing presentations on PowerPoint, all the while continually keeping the students' needs in mind while searching for appropriate visuals, animations, and websites. As research has shown, the IWB itself does not improve learning. Teachers must know how to connect their knowledge of the IWB with their knowledge of pedagogy so that they can make lessons that will not only engage the students, but that will enhance their learning. New technology by itself has no inherent pedagogical value. It must be properly used by those who are knowledgeable in their field of study. Increase variety of lessons. When preparing lessons for instruction, the IWB can aid in providing the variety that students thrive on. Just like adults, students easily tire of seeing the same things every day. The IWB allows teachers to draw on a plethora of resources. For example, a teacher who spends a little extra time and effort can often find Internet links to accompany lessons on many different topics. Teachers can also use the IWB to implement computer software that compliments the content that they are teaching. Features like PowerPoint can provide an engaging avenue for displaying lesson 
objectives or class notes. Sound effects and animations clearly add to these presentations, further engaging students and capturing their attention. In addition, the SMART Notebook feature provides an organized way to display lessons. While these lessons on PowerPoint or SMART Notebook take a significant amount of time and effort to prepare, they can all be saved for future use in years to come. As teachers become more comfortable and familiar with the IWB, the amount of time spent making lessons of the same caliber often diminishes. Teachers will become very efficient at preparing these lessons and presentations as they continually implement the IWB in their classrooms.

Increase student motivation and involvement in the classroom. Finally, the IWB can serve to increase student motivation and involvement in the classroom. In the present study, many students shared that they enjoyed interacting with the IWB. They looked forward to writing on the board, moving and dragging objects, and watching the animations and PowerPoint presentations. Students were eager to see what they were going to learn each day, and they were generally more eager to participate in the classroom discussion. In fact, in their journals and interviews, students shared that increased student interaction with the IWB is something that they desired in the future. One way this can be accomplished is to break the class into small groups or stations. Because only one person can write on the board at a time, smaller groups will allow for greater individual interaction with the IWB. The other groups can do other related tasks until their turn to use the IWB. Another method that was implemented during this study on several occasions was to put everyone's name on a popsicle stick and pull names so that every student had an equal opportunity to participate. To increase interaction not only with the IWB, but with the entire class, students can also be asked to solve a 
problem on the IWB and then stand at the front of the room and explain or teach what he/she did to the rest of the class. The students might even go so far as to use the fancy pens and highlight certain steps as they "teach" in order to help their classmates understand that particular problem.

\section{Biblical Integration}

There is often a lot of tension among Christians today concerning the use of technology, especially in schools. Many times technology is viewed as being evil...something that Christians should stay away from. It is true that technology can draw us away from Christ if it is used improperly. Yet, I do not believe that technology is bad in and of itself. Technology is simply a tool in our hands. We can use that tool to do harm, or we can use that tool to do great things. It is up to the person implementing the tool to determine the extent of its benefit or harm.

Before looking at something semi-controversial like technology and calling it "bad" or "evil," it is imperative to consider that even "good" things can ultimately drive us away from Christ if we are not careful. According to Keller (2008), sin is not just doing bad things. Sin is making good things into ultimate things. When we put anything, good or evil, ahead of our relationship with Jesus Christ, it is sin. Knowing this, Christian educators must constantly search their hearts to make sure that they are not putting technology, or work, or success, or anything else above Jesus Christ. When we lose our central focus, everything else will eventually fall apart.

As mentioned before, technology is a tool. I believe that if Christian educators are wise and practice discernment, they can use the IWB (a tool) in order to bring about positive changes. While "Jesus Christ is the same yesterday, today and forever," 
(Hebrews 13:8 New King James Version) everything around us is continually changing. As Christian educators, we can take the IWB as a good gift from above and use discretion in how we implement it in the classroom.

I believe that when Christian educators refuse to use a given resource like the IWB because of fear or stubbornness, they are missing out on many blessings. When I think back to the parable of the faithful steward in Luke 12:41-48, I am challenged to use the gifts that God has blessed me with. While I realize that this parable is referring to Christians using their spiritual riches in order to benefit others, I think that the case could also be made for using our natural blessings and gifts to benefit others. As a Christian teacher, if I am given an opportunity to use a resource like the IWB in my classroom, I can let it sit in my room gathering dust, or I can use it in way that would please my heavenly Father and bless my students in the process. My job as an educator is to help my students reach their full potential. My calling as God's servant is to minister to those young lives that $\mathrm{He}$ has placed in my care. If the IWB is a resource that might assist me in teaching my students, I believe that I should do all that I can to use it properly, efficiently, and in a way that would please and honor Jesus Christ.

\section{Suggestions for Future Research}

Because this study was conducted in a rural third grade classroom in a public school, it is necessary to explore the perspectives of other third grade students in both public and private schools. Furthermore, this study researched the perspectives of students who came from very similar backgrounds. Research is needed to examine the perspectives of third graders from different nationalities and backgrounds. It is also necessary to expand the study to analyze students' perceptions of the IWB in regards to 
subjects other than math, such as reading, English/language arts, social studies, science, art, and music.

Since the present study focused mainly on the qualitative issues surrounding students' perceptions of the IWB, future research should focus on examining the effects of the implementation of the IWB in the classroom in a quantitative manner. For example, the present study found that students perceive that the IWB helps them to learn. More studies could be conducted to quantitatively assess the effect of the IWB on students' academic achievement.

Finally, it would be beneficial to research primary teachers' perspectives of the IWB in the classroom setting. A qualitative study of this caliber would be invaluable in regards to making choices about how to improve instruction and pedagogy with the IWB in a primary classroom setting. 


\section{APPENDIX A}

\section{INTERVIEW QUESTIONS}

1. Compare the IWB to the overhead and/or chalkboard. What do you like about each and why?

\section{Benefits}

2. Everyone learns differently. Some students learn best by seeing, others learn best by hearing or by moving around. How do you think the IWB helps you learn, compared to the overhead or the chalkboard? Can you give some specific examples?

3. Compare your interest or excitement level in class when using the IWB versus the overhead. (In other words, are you more excited to use the IWB or the overhead/chalkboard? Or does it not matter to you?) If your interest or excitement level does change, explain how it changes? Why do you think it changes in this way?

4. Can you think of a specific time when the IWB changed your how interested you were in the lesson being taught? Explain how the IWB was used and why it caught your attention.

5. Compare the way the teacher teaches math when using the IWB compared to when she uses the overhead or chalkboard. Does her teaching style (how she 
teaches the lesson) change? If so, explain. Would you prefer the overhead/chalkboard or the IWB for math and why?

6. Would you prefer the overhead/chalkboard or the IWB for math and why?

7. Many visuals (i.e. pictures, diagrams, etc.) are often shown in class. Compare the quality of these visuals with the IWB versus with the overhead/chalkboard. (In other words, tell me how easily it is to see pictures or read words on both the IWB and the overhead/chalkboard.) Please be specific in the differences.

8. Think about the math lessons that we have learned in math class during this project. Can you think back to one or two lessons in particular where the IWB helped you to understand what your teacher was teaching? How did the IWB help?

\section{Limitations}

9. What do you not like about the IWB? Is anything distracting? In other words, is there anything about the IWB that keeps you from paying attention to the lesson being taught? Explain.

10. What problems have you noticed with the IWB? Give specific examples of any problems that have happened in class.

11. Have you personally been able to use the IWB? If so, how easy or how difficult is the IWB to use? Please be specific and explain why it is easy or difficult to use. 
12. How often have you been able to use the IWB? How do you feel about that? (In other words, do you wish you could use it more, or do you wish you could use it less?)

\section{Improvements}

13. Explain two things that your teacher could do with the IWB to make lessons more interesting.

14. Did you ever have any other teachers who used the IWB? If so, compare how I use it to how your other teacher(s) used the IWB.

15. What makes a teacher "good" at using the IWB. Explain.

16. In your own words, compare the IWB with the overhead/chalkboard. 


\section{APPENDIX B}

\section{PARENTAL CONSENT FORM}

Dear Parents/Guardians,

October $15^{\text {th }}, 2008$

For the past three years, I have been completing graduate courses leading to a Masters of Education Degree from Cedarville University in Ohio. This has been a wonderful learning experience for me, and I have been able to use much of what I have learned to provide the best education possible in my third grade classroom. As I near the completion of my Masters program, I am asking for your assistance in helping me to finish the program's final major requirement, my thesis/project.

In order to provide effective classroom instruction, I make use of a number of teaching techniques throughout the course of the school day. For example, I may choose to utilize the chalkboard, audio-visual devices such as the overhead projector, or technology tools like the interactive whiteboard (also referred to as the SMART Board). Unlike many other regional elementary schools, Glendale Elementary School is blessed to have an abundance of technology at their fingertips. Because each classroom is equipped with an interactive whiteboard (IWB), I have decided to devote my research to measuring the effectiveness of using this technology for instructional purposes. I am especially interested in the value that the students place on the IWB as I use it for instruction. My research will not only help me personally as I determine which teaching method to use more often in my classroom, but it will also be valuable to other teachers as they learn the students' perceptions of the advantages and disadvantages of using this technology within the classroom setting.

For the next eight weeks during math class, I will alternate using the IWB with the overhead projector and chalkboard for a total of eight weeks (two weeks with the IWB, two weeks without, etc.). Both of these methods are effective ways to teach new math concepts to students. Throughout this time period, I will ask your son/daughter to answer several key questions concerning his/her perceptions of the use of the IWB in the classroom. Answers to the daily questions as well as other comments will be recorded in the students' personal journals. At the end of the eight-week period, I will conduct a 1015 minute interview with each participating student. Interviews will take place over the children's lunch break (as your child and I have lunch together) or during my prep period at the end of the day (only if necessary). In addition, a focus group may be formed to gather students' collective ideas regarding the IWB.

At this time, I am requesting permission for your son/daughter to be interviewed by me and to have his/her opinions used in my paper. Please note that (1) participation in the interview process is completely voluntary, (2) the interview will be taped by audio cassette so that I may accurately transcribe the information shared during the interview, and (3) all information will be kept confidential (students' real names will not be used in the final paper). 
Please complete and return the attached permission form to me by Friday, October $17^{\text {th }}$. Thank you for your participation and cooperation. Please feel free to contact me if you have any questions or concerns.

Sincerely,

Miss Genesi

Please complete the permission form below and return to me by Friday, October $17^{\text {th }}$. I will begin my research project on Monday, October $20^{\text {th }}$. Thank you so much for your cooperation!

I DO give permission for my child to participate in an interview regarding his/her perceptions of the IWB. I also grant permission for the interview to be taped and transcribed. I understand that confidentiality will be maintained.

I DO NOT give permission for my child to participate in an interview regarding his/her perceptions of the IWB.

Student's Name:

Parent/Guardian's Signature:

Date:

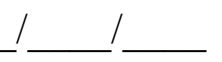




\section{References}

Albirini, A. (2006). Teachers' attitudes toward information and communication technologies: The case of Syrian EFL teachers. Computers \& Education, 47(4; 4), 373-398.

Armstrong, V., Barnes, S., Sutherland, R., Curran, S., Mills, S., \& Thompson, I. (2005). Collaborative research methodology for investigating teaching and learning: The use of interactive whiteboard technology. Educational Review, 57(4), 457-469.

Beauchamp, G., \& Parkinson, J. (2008). Pupils' attitudes towards school science as they transfer from an ICT-rich primary school to a secondary school with fewer ICT resources: Does ICT matter? Education \& Information Technologies, 13(2; 2), 103 118.

Beeland, W.D. (2002). Student engagement, visual learning, and technology: A report on 10 years of ACOT research. Retrieved February 14, 2009, from http://education.smarttech.com/ste/enUS/News+and+research/Research/International/US/2002/Student+Engagement.htm

Burns, C., \& Myhill, D. (2004). Interactive or inactive? A consideration of the nature of interaction in whole class teaching. Cambridge Journal of Education, 34(1), 35-49.

Clyde, L. A. (2004). Electronic whiteboards. Teacher Librarian, 32(2; 2), 43-44.

DenBeste, M. (2003). Power point, technology and the web: More than just an overhead projector for the new century? History Teacher, 36(4), 491-504. 
Driscoll, M. P. (2002). How people learn (and what technology might have to do with it. Syracuse, NY: ERIC Clearinghouse on Information and Technology. (ERIC Document Reproduction Service No. ED470032)

Fletcher, G. H. (2006). Imagine the possibilities T.H.E. Journal.

Furr, P., Ragsdale, R., \& Horton, S. (2005). Technology's non-neutrality: Past lessons can help guide Today's classrooms. Education \& Information Technologies, 10(3; 3), 277-287.

Gillen, J., Littleton, K., Twiner, A., Staarman, J. K., \& Mercer, N. (2008). Using the interactive whiteboard to resource continuity and support multimodal teaching in a primary science classroom. Journal of Computer Assisted Learning, 24(4; 4), 348358.

Gillen, J., Staarman, J. K., Littleton, K., Mercer, N., \& Twiner, A. (2007). A 'learning revolution'? investigating pedagogic practice around interactive whiteboards in british primary classrooms. Learning, Media, \& Technology, 32(3; 3), 243-256.

Glover, D., \& Miller, D. (2003). Players in the management of change: Introducing interactive whiteboards into schools. Management in Education, 17(1), 20-23.

Glover, D., \& Miller, D. (2007). Leading changed classroom culture -- the impact of interactive whiteboards. Management in Education (Sage Publications Inc.), 21(3), $21-24$ 
Hall, I., \& Higgins, S. (2005). Primary school students' perceptions of interactive whiteboards. Journal of Computer Assisted Learning, 21(2; 2), 102-117.

Hargreaves, L., Moyles, J., Merry, R., Paterson, F., Pell, A., \& Esarte-Sarries, V. (2003). How do primary school teachers define and implement 'interactive teaching' in the national literacy strategy in England? Research Papers in Education, 18(3), 217236.

Introduction-What is ICT? (2006). Retrieved February 14, 2009, from http://www.tutor2u.net/business/ict/intro_what_is_ict.htm

Jones, K. (2004) Using interactive whiteboards in the teaching and learning of mathematics: a research bibliography. MicroMath, 20(2), 5-6.

Keller, T. (2008). The reason for God: Belief in an age of skepticism. New York, New York: Penguin Group (USA) Inc.

Kelley, P., Underwood, G., Potter, F., Hunter, J., \& Beveridge, S. (2007). Viewpoints. Learning, Media, \& Technology, 32(3), 333-347.

Kennewell, S., \& Beauchamp, G. (2007). The features of interactive whiteboards and their influence on learning. Learning, Media, \& Technology, 32(3), 227-241.

Kennewell, S., Tanner, H., Jones, S., \& Beauchamp, G. (2008). Analysing the use of interactive technology to implement interactive teaching. Journal of Computer Assisted Learning, 24(1), 61-73. 
Kent, N., \& Facer, K. (2004). Different worlds? A comparison of young people's home and school ICT use. Journal of Computer Assisted Learning, 20(6), 440-455.

Kent, P. (2006). Using interactive whiteboards to enhance mathematics teaching. Australian Primary Mathematics Classroom, 11(2), 23-26.

Kirkwood, A., \& Price, L. (2005). Learners and learning in the twenty $\square$ first century: What do we know about students' attitudes towards and experiences of information and communication technologies that will help us design courses? Studies in Higher Education, 30(3), 257-274.

Knight, P., Pennant, J., \& Piggott, J. (2004). What does it mean to "use the interactive whiteboard" in the daily mathematics lesson? Micro Math, 20(2), 14-16.

Landis, M. (2005, March/April). Eight ways to integrate whiteboard into instruction. Media and Methods, 41, 4.

Lawrenz, F., Gravely, A., \& Ooms, A. (2006). Perceived helpfulness and amount of use of technology in science and mathematics classes at different grade levels. Technology in Science and Mathematics Classes, 106, 133-139.

Lei, J., \& Zhao, Y. (2007). Technology uses and student achievement: A longitudinal study. Computers \& Education, 49(2), 284-296.

Mackall, P. (2004). Interactive whiteboards enhance the learning experience for deaf, hard-of-hearing students. T H E Journal, 31(10; 10), 64-66. 
Mechling, L. C., Gast, D. L., \& Thompson, K. L. (2008). Comparison of the effects of smart board technology and flash card instruction on sight word recognition and observational learning. Journal of Special Education Technology, 23(1; 1), 34-46.

Merrett, S., \& Edwards, J. (2005). Enhancing mathematical thinking with an interactive whiteboard. Micro Math, 21(3), 9-12.

Ozel, S., Ebrar Yetkiner, Z., \& Capraro, R. M. (2008). Technology in K-12 mathematics classrooms. School Science \& Mathematics, 108(2), 80-85.

Pountain, D. (2001). The new penguin dictionary of computing: An a-z of computing jargon and concepts. London: Penguin Books, Ltd.

Reardon, T. (2002). Interactive whiteboards in school: Effective uses. Media \& Methods, $38(7), 12$.

Schut, C. R. (2007). Student perceptions of interactive whiteboards in a biology classroom (Master's thesis, Cedarville University, 2007).

Schweder, W., Wissick, C. A., \& Mounce, A. B. (2008). Teaching content with interactive whiteboards. Journal of Special Education Technology, 23(1; 1), 54-58.

Shenton, A., \& Pagett, L. (2007). From 'bored' to screen: The use of the interactive whiteboard for literacy in six primary classrooms in england. Literacy, 41(3; 3), 129136. 
SMART Technologies, Company Info. (2006). Retrieved February 14, 2009, from http://www2.smarttech.com/st/en-US/About+Us/Company+Info/History.htm

Smith, H. J., Higgins, S., Wall, K., \& Miller, J. (2005). Interactive whiteboards: Boon or bandwagon? A critical review of the literature. Journal of Computer Assisted Learning, 21(2), 91-101.

Starkman, N. (2006). The wonders of interactive WHITEBOARDS. T H E Journal, 33(10), 36-38.

Sutherland, R., Armstrong, V., Barnes, S., Brawn, R., Breeze, N., Gall, M., et al. (2004). Transforming teaching and learning: Embedding ICT into everyday classroom practices. Journal of Computer Assisted Learning, 20(6), 413-425.

Tanner, H., \& Jones, S. (2007). Using video-stimulated reflective dialogue to learn from children about their learning with and without ICT. Technology, Pedagogy \& Education, 16(3; 3), 321-335.

The CEO Forum on Education and Technology (2001). School technology and readiness report: Key building blocks for student achievement in the $21^{\text {st }}$ century: assessment, alignment, accountability, access, analysis. Washington, DC: Author. Retrieved February 14, 2009, from http://www.ceoforum.org/downloads/report4.pdf

Vail, K. (2003). School technology grows up. American School Board Journal, 190(9), $34-37$. 
Venezky, R. L. (2004). Technology in the classroom: Steps toward a new vision. Education, Communication \& Information, 4(1), 3-21.

Villano, M. (2006). Picture this! T H E Journal, 33(16), 16-20.

Wall, K., Higgins, S., \& Smith, H. (2005). 'The visual helps me understand the complicated things': Pupil views of teaching and learning with interactive whiteboards. British Journal of Educational Technology, 36(5), 851-867.

Wheeler, S. (2001). Information and communication technologies and the changing role of the teacher. Journal of Educational Media, 26(1), 7-17.

Williams, D., Coles, L., Wilson, K., Richardson, A., \& Tuson, J. (2000). Teachers and ICT: Current use and future needs. British Journal of Educational Technology, 31(4), 307-320.

Zhang, S. \& Deng, H. (2004). Perception of learning effectiveness in the multimedia classroom vs. the traditional classroom: A case study. Media Review, 11, 87-107.

Ziolkowski, R. (2004). Interactive whiteboards: Impacting teaching and learning. Media \& Methods, 40(4), 44-44. 